\title{
Water-Induced Structural Changes in Crown Ethers from Broadband Rotational Spectroscopy
}

Cristóbal Pérez ${ }^{1,2}$, Juan C. López ${ }^{1,3^{*}}$, Susana Blanco ${ }^{3}$ and Melanie Schnel1 ${ }^{1,2}$.

${ }^{1}$ Max Planck Institute for the Structure and Dynamics of Matter, Hamburg (Germany).

${ }^{2}$ The Hamburg Centre for Ultrafast Imaging at the Universität Hamburg, Hamburg (Germany).

${ }^{3}$ Departamento de Quimica Fisica y Quimica Inorganica, Facultad de Ciencias, Universidad de Valladolid, Valladolid (Spain).

*To whom correspondence should be addressed: Juan Carlos Lopez Melanie Schnell jclopez@qf.uva.es, melanie.schnell@mpsd.mpg.de

\section{Tables of supplementary material}

Contents:

Complete reference [21]

21 Tables

7 figures 
Complete reference [21]

Gaussian 09, Revision E.01, M. J. Frisch, G. W. Trucks, H. B. Schlegel, G. E. Scuseria, M. A. Robb, J. R. Cheeseman, G. Scalmani, V. Barone, B. Mennucci, G. A. Petersson, H. Nakatsuji, M.

Caricato, X. Li, H. P. Hratchian, A. F. Izmaylov, J. Bloino, G. Zheng, J. L. Sonnenberg, M. Hada, M. Ehara, K. Toyota, R. Fukuda, J. Hasegawa, M. Ishida, T. Nakajima, Y. Honda, O. Kitao, H. Nakai, T. Vreven, J. A. Montgomery, Jr., J. E. Peralta, F. Ogliaro, M. Bearpark, J. J. Heyd, E. Brothers, K. N. Kudin, V. N. Staroverov, R. Kobayashi, J. Normand, K. Raghavachari, A. Rendell, J. C. Burant, S. S. Iyengar, J. Tomasi, M. Cossi, N. Rega, J. M. Millam, M. Klene, J. E. Knox, J. B. Cross, V.

Bakken, C. Adamo, J. Jaramillo, R. Gomperts, R. E. Stratmann, O. Yazyev, A. J. Austin, R. Cammi, C. Pomelli, J. W. Ochterski, R. L. Martin, K. Morokuma, V. G. Zakrzewski, G. A. Voth, P. Salvador, J. J. Dannenberg, S. Dapprich, A. D. Daniels, Ö. Farkas, J. B. Foresman, J. V. Ortiz, J. Cioslowski, and D. J. Fox, Gaussian, Inc., Wallingford CT, 2009. 
Table S1. Spectroscopic parameters and energies predicted (MP2/6-311++G(d, p)) for the low-energy conformers of $12 \mathrm{C} 4$ ether.

\begin{tabular}{|c|c|c|c|c|c|c|c|c|}
\hline & $\mathrm{Cl}\left(S_{4}\right)$ & $\operatorname{CII}\left(C_{\mathrm{i}}\right)$ & $\operatorname{CIII}\left(C_{1}\right)$ & $\operatorname{CIV}\left(C_{1}\right)$ & $\mathbf{C V}\left(C_{1}\right)$ & $\operatorname{CVI}\left(C_{1}\right)$ & $\operatorname{CVII}\left(C_{1}\right)$ & CVIII $\left(C_{1}\right)$ \\
\hline Torsions $^{a}$ & $0+-0-+0+-0-+$ & $0-+0++0+-0--$ & $0+00-+-00+-0$ & $0-00++0+-0--$ & $0--0-+0+-0$ & $0++0+00-+0++$ & $0-+0++-+0++0$ & $+--0-00+-+0+$ \\
\hline $\mathrm{A} / \mathrm{MHz}$ & 994.0 & 1080.5 & 1176.6 & 1129.1 & 1007.3 & 1110.0 & 1061.3 & 1173.6 \\
\hline $\mathrm{B} / \mathrm{MHz}$ & 994.0 & 876.8 & 795.5 & 855.7 & 950.2 & 860.6 & 896.3 & 820.5 \\
\hline $\mathrm{C} / \mathrm{MHz}$ & 613.3 & 528.7 & 505.9 & 536.1 & 551.8 & 528.8 & 540.2 & 526.2 \\
\hline$\kappa$ & 1.00 & 0.26 & -0.14 & 0.08 & 0.75 & 0.14 & 0.37 & -0.09 \\
\hline $\mathrm{P}_{\mathrm{aa}} / \mathrm{u} \AA^{2}$ & 411.90 & 532.30 & 602.34 & 542.87 & 473.01 & 543.84 & 511.60 & 572.89 \\
\hline $\mathrm{P}_{\mathrm{bb}} / \mathrm{u} \AA^{2}$ & 411.90 & 423.63 & 396.55 & 399.87 & 442.83 & 411.89 & 423.93 & 387.54 \\
\hline $\mathrm{P}_{\mathrm{cc}} / \mathrm{u} \AA^{2}$ & 96.48 & 44.07 & 32.98 & 47.72 & 58.87 & 43.41 & 52.27 & 43.09 \\
\hline$\mu_{\mathrm{a}} / \mathrm{D}$ & 0.0 & 0.0 & -0.7 & 0.7 & 1.8 & -0.3 & 0.4 & -0.3 \\
\hline$\mu_{\mathrm{b}} / \mathrm{D}$ & 0.0 & 0.0 & 2.9 & 1.5 & -0.2 & -1.0 & 1.7 & 3.2 \\
\hline$\mu_{\mathrm{c}} / \mathrm{D}$ & 0.0 & 0.0 & -0.1 & 0.2 & 2.1 & 2.7 & 1.7 & 1.7 \\
\hline$\mu_{T} / D$ & 0.0 & 0.0 & 3.0 & 1.7 & 2.7 & 2.9 & 2.4 & 3.6 \\
\hline$\Delta \mathrm{E} / \mathrm{cm}^{-1}$ & 0 & 696 & 684 & 810 & 796 & 850 & 1017 & 814 \\
\hline$\Delta \mathrm{G} / \mathrm{cm}^{-1}$ & 0 & 237 & 384 & 390 & 438 & 449 & 508 & 667 \\
\hline $\mathrm{N}_{\mathrm{i}} / \mathrm{N}_{\mathrm{C} 1}$ & 1.00 & 0.45 & 0.27 & 0.27 & 0.23 & 0.22 & 0.18 & 0.10 \\
\hline
\end{tabular}

${ }^{a}$ Sign of the torsional angles for the conformers of 12C4 of the four C-O-C-C-O-C groups. First torsional angle is defined by the sequence of atoms $\mathrm{C}_{1} \mathrm{O}_{2} \mathrm{CC}$ (+ is taken for angles from 0 to $2 / 3 \pi$; - for angles between 0 and $-2 / 3 \pi$, and 0 for angles between $2 / 3 \pi$ and $4 / 3 \pi$ ), 
Figure S1. Low-energy conformers of $12 \mathrm{C} 4$ as predicted by ab initio computations. The labeling of the carbon and oxygen atoms (1 and 2, respectively) serves to evaluate the torsional angles as indicated in qualitative notation below (see Table S1).

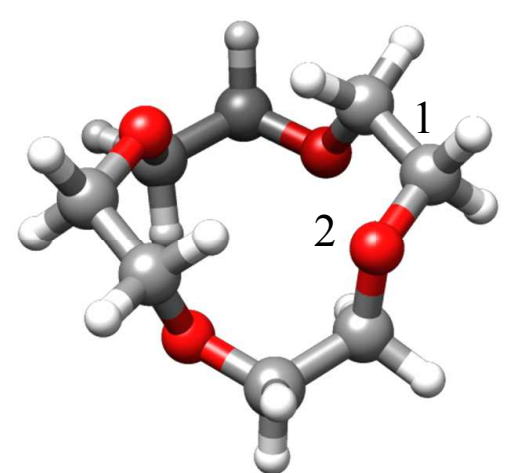

CI

0+-0-+0+-0-+

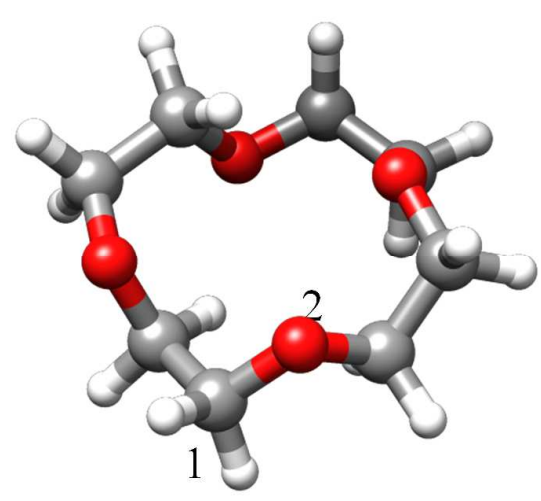

CV

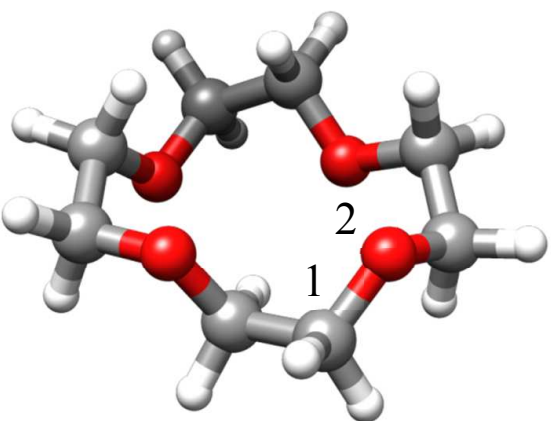

CII

0-+0++0+-0--

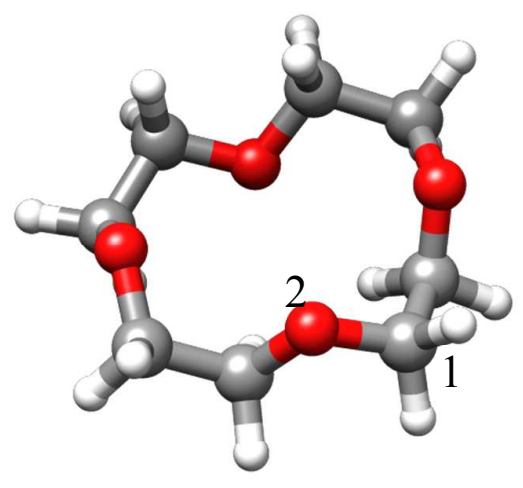

CVI

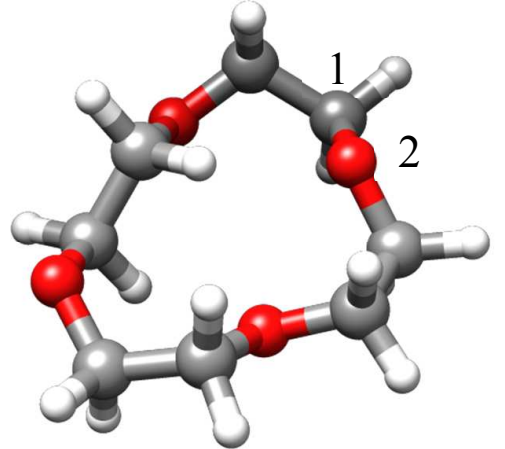

CIII

0+00-+-00+-0

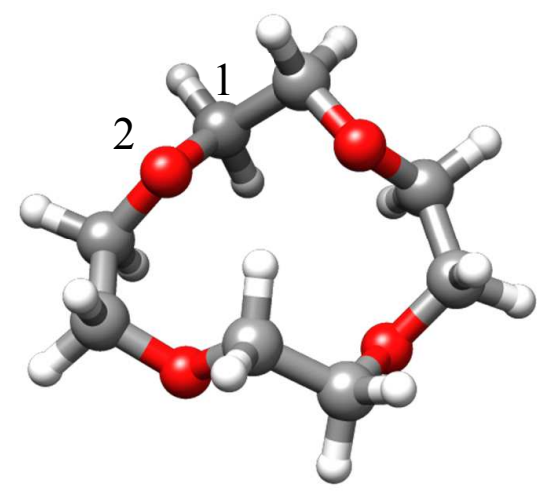

CVII

0-+0++-+0++0

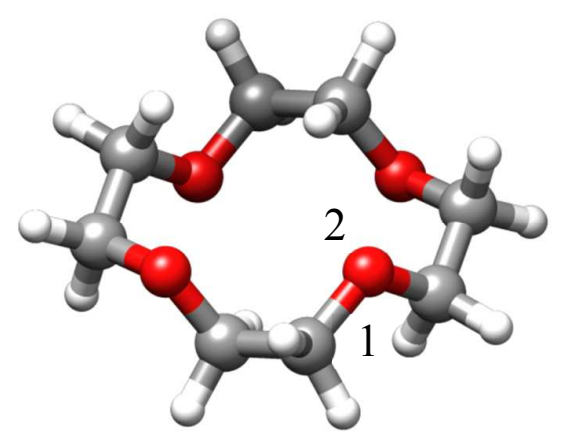

CIV

0-00++0+-0--

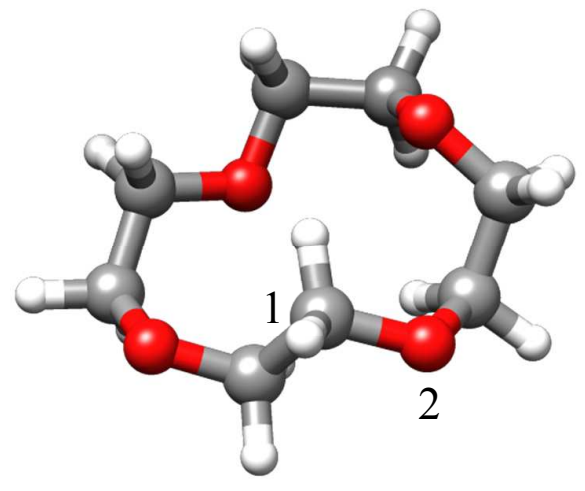

CVIII

+--0-00+-+0+ 
Table S2. Spectroscopic parameters and energies predicted (MP2/6-311++G(d, p)) for some clusters of 12C4-water. Conformers CIV-WI, CIV-WII and CIV-W $\mathbf{W}_{2}$ result from optimizations starting with either the $12 \mathrm{C} 4 \mathrm{CII}$ or the CIV conformer. The final structure of $12 \mathrm{C} 4$ in the complex is in all cases close to the CIV form.

\begin{tabular}{r|rrrrrrr}
\hline & \multicolumn{1}{|c}{ CIV-WI } & \multicolumn{1}{c}{ CIV-WII } & \multicolumn{1}{c}{ CI-WI } & \multicolumn{1}{c}{ CI-WII } & \multicolumn{1}{c}{ CIII-WI } & \multicolumn{1}{c}{ CIII-WII } & \multicolumn{1}{c}{ CIV-W $\mathbf{2}$} \\
\hline $\mathrm{A} / \mathrm{MHz}$ & 889.2 & 858.6 & 884.8 & 803.5 & 923.7 & 903.3 & 639.7 \\
$\mathrm{~B} / \mathrm{MHz}$ & 699.1 & 716.7 & 641.0 & 718.1 & 663.3 & 616.0 & 537.9 \\
$\mathrm{C} / \mathrm{MHz}$ & 539.4 & 534.4 & 484.2 & 593.5 & 500.3 & 482.1 & 501.2 \\
$\kappa$ & -0.1 & 0.1 & -0.2 & 0.2 & -0.2 & -0.4 & -0.5 \\
$\mathrm{P}_{\mathrm{aa}} / \mathrm{u} \AA^{2}$ & 545.7 & 531.2 & 630.5 & 463.1 & 612.5 & 654.6 & 578.9 \\
$\mathrm{P}_{\mathrm{bb}} / \mathrm{u}^{2}$ & 391.2 & 414.6 & 413.2 & 388.4 & 397.7 & 393.6 & 429.5 \\
$\mathrm{P}_{\mathrm{cd}} \mathrm{u} \AA^{2}$ & 177.2 & 174.0 & 157.9 & 240.6 & 149.4 & 165.8 & 360.6 \\
$\mu_{\mathrm{a}} / \mathrm{D}$ & 0.4 & -0.4 & 0.6 & 0.0 & 0.5 & 0.0 & 1.1 \\
$\mu_{\mathrm{b}} / \mathrm{D}$ & 0.6 & 0.2 & 1.9 & 0.0 & 2.1 & 1.0 & 0.9 \\
$\mu_{\mathrm{d}} / \mathrm{D}$ & -1.2 & -1.3 & 0.2 & -2.6 & -2.3 & -0.3 & 1.0 \\
$\mu_{\mathrm{T}} / \mathrm{D}$ & 1.4 & 1.4 & 2.0 & 2.6 & 3.2 & 1.1 & 5.1 \\
$\Delta \mathrm{E} / \mathrm{cm}^{-1}$ & 0.0 & 204.2 & 625.8 & 747.1 & 896.6 & 1022.9 & \\
\hline
\end{tabular}


Figure S2. Low-energy conformers of $12 \mathrm{C} 4$-water as predicted by ab initio computations. Conformers C5-wa, C5-wb and C5-w 2 result from optimizations starting with either the $12 \mathrm{C} 4 \mathrm{C} 3$ or the $\mathrm{C} 5$ conformer. The final structure of $12 \mathrm{C} 4$ in the complex is in all cases close to the $\mathrm{C} 5$ form.
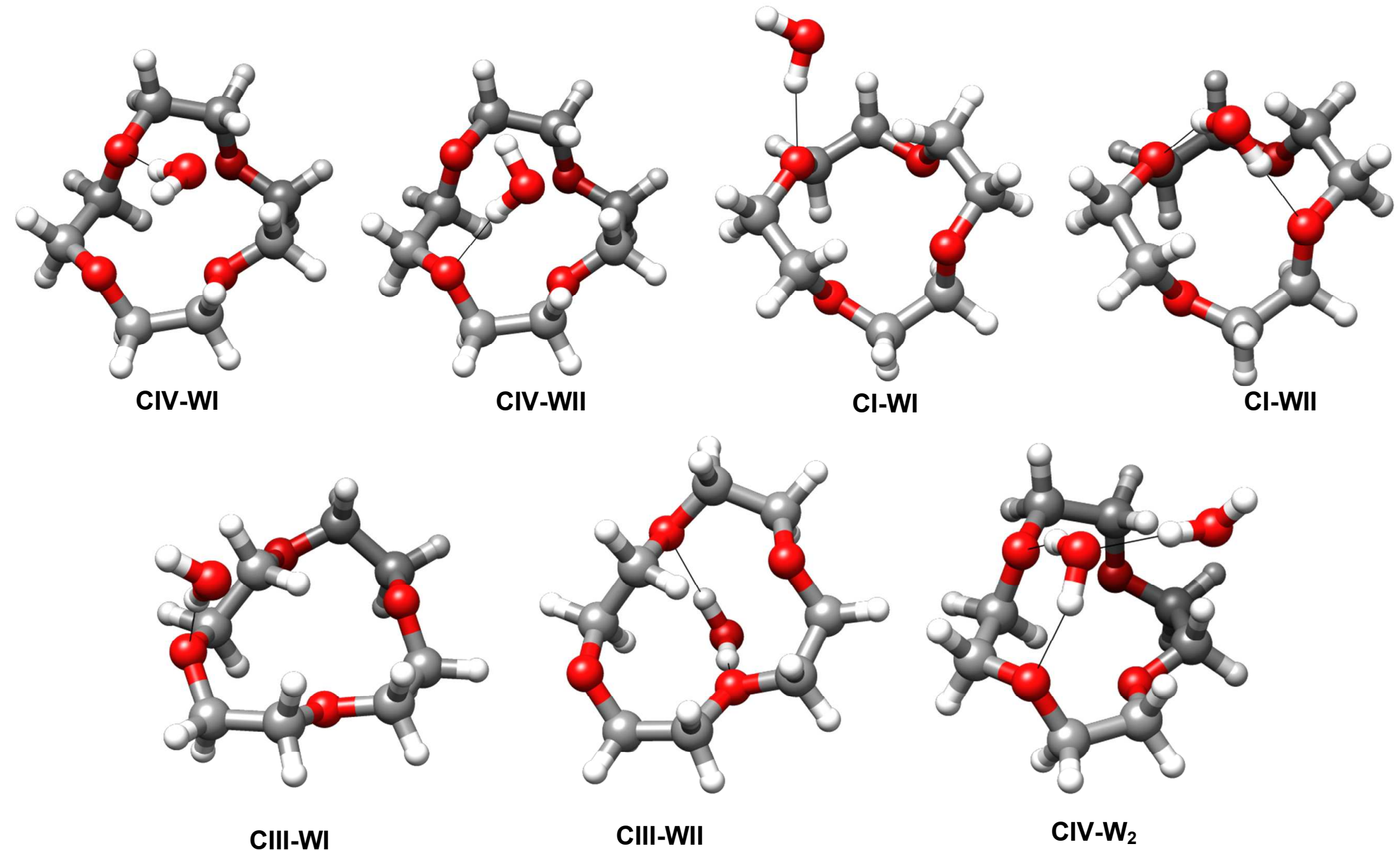

CIII-WI

CIII-WII 
Figure S3. The correlation between $C$ rotational constant and $P_{\mathrm{cc}}$ planar moment for 12 -crown-4 ether

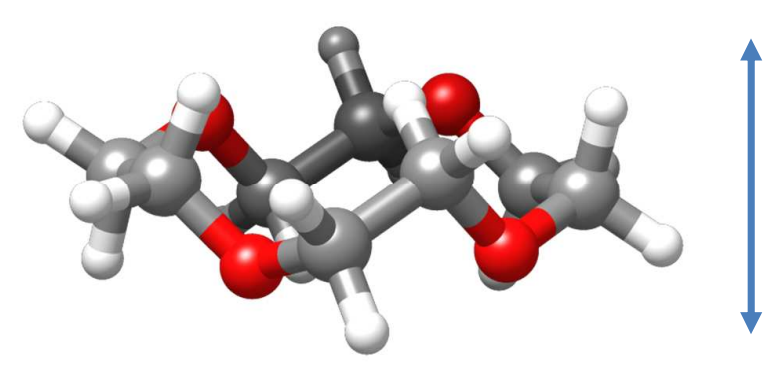

$$
P_{c c}=\left(I_{a}+I_{b}-I_{c}\right) / 2=\sum_{i} m_{i} c_{i}^{2}
$$

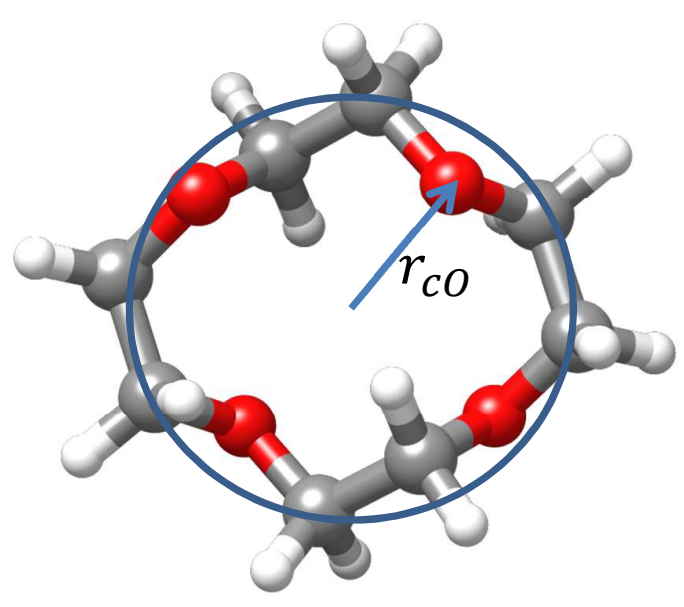

$$
I_{c}=\sum_{i} m_{i}\left(a_{i}^{2}+b_{i}^{2}\right)=\sum_{i} m_{i} r_{c i}^{2}
$$


Figure S4. Broadband spectrum of 12-crown-4-ether from 2-8 GHz

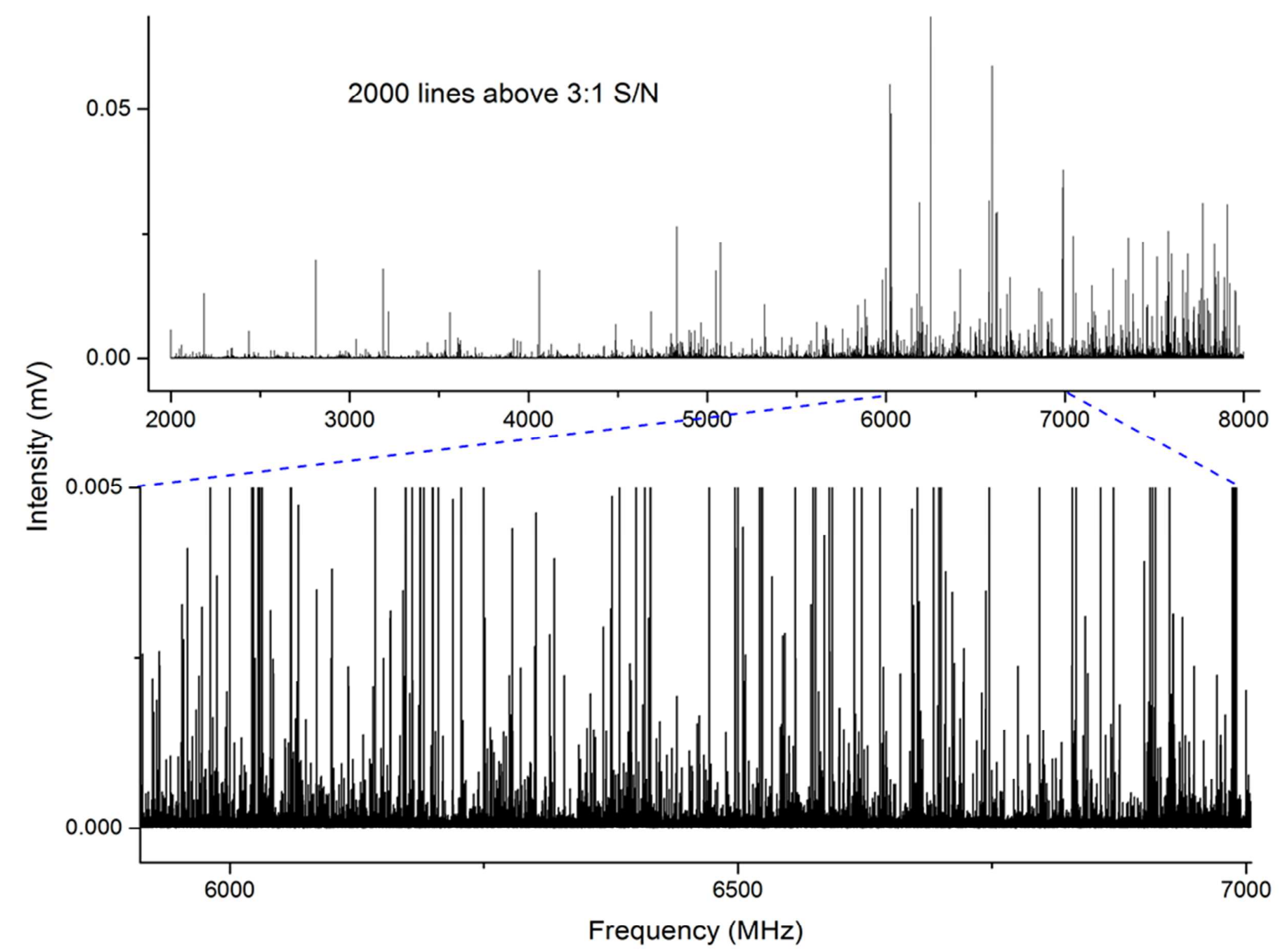


Table S3. Rotational parameters obtained from the analysis of the spectrum of the 12-crown-4 ether $\cdots \mathrm{H}_{2} \mathrm{O}$ conformer labelled $\mathbf{C l}-\mathbf{W I}$ (see Table 1 of the main text).

\begin{tabular}{|c|c|c|c|c|c|c|c|c|}
\hline & Parent Species & calc. & ${ }^{18} \mathrm{O}_{\mathrm{w}}\left(\mathrm{H}_{2} \mathrm{O}\right)$ & & ${ }^{13} \mathrm{C}_{2}$ & ${ }^{13} \mathrm{C}_{3}$ & ${ }^{13} \mathrm{C}_{5}$ & ${ }^{13} \mathrm{C}_{6}$ \\
\hline$A^{\mathrm{a}} / \mathrm{MHz}$ & $859.605198(18)^{b}$ & 884.8 & $853.95816(38)$ & $\mathrm{A} / \mathrm{MHz}$ & $852.16098(97)$ & $853.7049(26)$ & $858.6195(17)$ & $858.83573(75)$ \\
\hline $\mathrm{B} / \mathrm{MHz}$ & $634.96607(17)$ & 641.0 & $613.48496(27)$ & $\mathrm{B} / \mathrm{MHz}$ & $634.54034(60)$ & $633.7974(76)$ & $629.2133(12)$ & 630.07652 (69) \\
\hline $\mathrm{C} / \mathrm{MHz}$ & $482.06588(15)$ & 484.2 & $471.22821(12)$ & $\mathrm{C} / \mathrm{MHz}$ & $479.54673(22)$ & $480.06056(51)$ & $478.42968(32)$ & $479.13732(33)$ \\
\hline$P_{\mathrm{a}} / \mathrm{u} \AA^{2}$ & 628.17798(28) & 630.5 & $652.22403(45)$ & & & & & \\
\hline$P_{\mathrm{b}} / \mathrm{u} \AA^{2}$ & $420.18290(28)$ & 413.2 & $420.24786(45)$ & $\sigma / k H z$ & 6.5 & 20.9 & 11.3 & 7.9 \\
\hline$P_{\mathrm{c}} / \mathrm{u} \AA^{2}$ & $167.73701(28)$ & 157.9 & $171.55983(45)$ & $\mathrm{n}$ & 14 & 11 & 12 & 11 \\
\hline$\Delta_{\lrcorner} / \mathrm{kHz}$ & $0.1675(18)$ & 0.113 & & & & & & \\
\hline$\Delta_{\mathrm{JK}} / \mathrm{kHz}$ & $-0.4604(52)$ & -0.232 & & & ${ }^{13} \mathrm{C}_{8}$ & ${ }^{13} \mathrm{C}_{9}$ & ${ }^{13} \mathrm{C}_{11}$ & ${ }^{13} \mathrm{C}_{12}$ \\
\hline$\Delta_{\mathrm{K}} / \mathrm{kHz}$ & $0.7887(56)$ & 0.420 & & $\mathrm{~A} / \mathrm{MHz}$ & $851.7586(16)$ & $853.74927(62)$ & $855.31993(81)$ & $856.00691(61)$ \\
\hline$\delta_{\mathrm{J}} / \mathrm{kHz}$ & $0.00954(77)$ & 0.015 & & $\mathrm{~B} / \mathrm{MHz}$ & $633.7604(16)$ & $634.75158(69)$ & $631.26922(45)$ & $631.98392(84)$ \\
\hline$\delta_{\mathrm{k}} / \mathrm{kHz}$ & $0.0869(38)$ & 0.061 & & $\mathrm{C} / \mathrm{MHz}$ & $479.35548(38)$ & $480.14186(29)$ & $480.66444(19)$ & $481.07503(25)$ \\
\hline$\sigma / \mathrm{kHz}$ & 4.3 & & 6.1 & $\sigma / k H z$ & 11.3 & 8.0 & 6.5 & 6.3 \\
\hline$n$ & 136 & & 26 & $\mathrm{n}$ & 12 & 16 & 20 & 13 \\
\hline
\end{tabular}

${ }^{a}$ Analysis of the spectra have been done with the A-reduced semirigid rotor Hamiltonian of Watson ${ }^{[16]}$ in the I representation. A, B and C are the rotational constants; $\Delta_{\mathrm{J}}, \Delta_{\mathrm{JK}}, \Delta_{\mathrm{K}}, \delta_{\mathrm{J}}$ and $\delta_{\mathrm{K}}$ are the quartic centrifugal distortion constants, which have been fixed to the parent species values for the spectra of isotopologues; $\sigma$ is the rms deviations of the fit; $n$ is the number of lines fitted. ${ }^{b}$ Standard errors are given in parentheses in units of the last digit. 
Table S4. Rotational parameters obtained from the analysis of the spectrum of the 12-crown-4 ether $\cdots \mathrm{H}_{2} \mathrm{O}$ conformer labelled CIV-WI in Table 1 of the main text.

\begin{tabular}{llll}
\hline Parameter $^{\mathrm{a}}$ & Parent Species & calc. & ${ }^{18} \mathrm{O}_{\mathrm{w}}\left(\mathrm{H}_{2} \mathrm{O}\right)$ \\
\hline$A / \mathrm{MHz}$ & $865.68041(57)^{\mathrm{b}}$ & 889.2 & $845.95985(53)$ \\
$\mathrm{B} / \mathrm{MHz}$ & $692.14048(89)$ & 699.1 & $679.79073(34)$ \\
$\mathrm{C} / \mathrm{MHz}$ & $534.66454(78)$ & 539.4 & $534.39087(31)$ \\
$P_{\mathrm{a}} / \mathrm{u} \AA^{2}$ & $545.8003(13)$ & 545.7 & $545.87028(65)$ \\
$P_{\mathrm{b}} / \mathrm{u} \AA^{2}$ & $399.4260(13)$ & 391.2 & $399.84013(65)$ \\
$P_{\mathrm{c}} / \mathrm{u} \AA^{2}$ & $184.3680(13)$ & 177.2 & $197.56294(65)$ \\
$\Delta_{\mathrm{J}} / \mathrm{kHz}$ & $0.0555(99)$ & 0.031 & {$[0.0555]$} \\
$\Delta_{\mathrm{JK}} / \mathrm{kHz}$ & {$[0 .]^{\mathrm{c}}$} & 0.091 & {$[0.0]$} \\
$\Delta_{\mathrm{K}} / \mathrm{kHz}$ & {$[0]$.} & -0.001 & {$[0.0]$} \\
$\delta_{\mathrm{J}} / \mathrm{kHz}$ & $-0.0196(54)$ & 0.009 & {$[-0.0196]$} \\
$\delta_{\mathrm{k}} / \mathrm{kHz}$ & {$[0]$.} & -0.006 & {$[0.0]$} \\
$\sigma / \mathrm{kHz}$ & 4.0 & \multicolumn{3}{l}{} \\
$n$ & 75 &
\end{tabular}


Table S5. Rotational parameters obtained from the analysis of the spectrum of the 12-crown-4 ether $\cdots \mathrm{H}_{2} \mathrm{O}$ rotamer labelled

CIV-WII in Table 1 of the main text.

\begin{tabular}{lll}
\hline Parameter $^{\mathrm{a}}$ & \multicolumn{1}{c}{ Exp. } & \multicolumn{1}{c}{ Calc. } \\
\hline$A / \mathrm{MHz}$ & $858.65138(36)^{\mathrm{b}}$ & 858.6 \\
$B / \mathrm{MHz}$ & $726.04533(57)$ & 716.7 \\
$\mathrm{C} / \mathrm{MHz}$ & $520.96955(55)$ & 534.4 \\
$P_{\mathrm{a}} / \mathrm{u} \AA^{2}$ & $538.78594(91)$ & 531.2 \\
$P_{\mathrm{b}} / \mathrm{u} \AA^{2}$ & $431.28805(91$ & 414.6 \\
$P_{\mathrm{c}} / \mathrm{u} \AA^{2}$ & $157.28494(91)$ & 174.0 \\
$\Delta_{\mathrm{J}} / \mathrm{kHz}$ & {$[0 .]^{\mathrm{c}}$} & 0.088 \\
$\Delta_{\mathrm{JK}} / \mathrm{kHz}$ & {$[0]$.} & -0.088 \\
$\Delta_{\mathrm{K}} / \mathrm{kHz}$ & {$[0]$.} & 0.011 \\
$\delta_{\mathrm{J}} / \mathrm{kHz}$ & $-0.0815(81)$ & 0.013 \\
$\delta_{\mathrm{k}} / \mathrm{kHz}$ & {$[0]$.} & -0.029 \\
$\sigma / \mathrm{kHz}$ & 5.2 & \\
$n$ & 21 & \\
\hline
\end{tabular}

${ }^{a} A, B$ and $C$ are the rotational constants; $\Delta_{\mathrm{J}}, \Delta_{\mathrm{JK}}, \Delta_{\mathrm{K}}, \delta_{\mathrm{J}}$ and $\delta_{\mathrm{K}}$ are the quartic centrifugal distortion constants; $\sigma$ is the rms deviations of the fit; $n$ is the number of lines fitted. ${ }^{b}$ Standard errors are given in parentheses in units of the last digit. ${ }^{c}$ Parameters in square brackets are fixed to the quoted values. 
Table S6. Rotational parameters obtained from the analysis of the spectrum of the 12-crown-4 ether $\cdots\left(\mathrm{H}_{2} \mathrm{O}\right)_{2}$ conformer CIV-W $\mathbf{2}$

\begin{tabular}{|c|c|c|c|c|}
\hline Parameter $^{a}$ & Parent Species & calc & ${ }^{18} \mathrm{O}_{\mathrm{w}}(1)\left(\mathrm{H}_{2} \mathrm{O}\right)$ & ${ }^{18} \mathrm{O}_{\mathrm{w}}(2)\left(\mathrm{H}_{2} \mathrm{O}\right)$ \\
\hline$A / \mathrm{MHz}$ & $620.65214(33)^{b}$ & 639.7 & $611.32457(16)$ & $606.11663(17)$ \\
\hline $\mathrm{B} / \mathrm{MHz}$ & $528.67490(24)$ & 537.9 & $521.79637(14)$ & $517.27361(16)$ \\
\hline $\mathrm{C} / \mathrm{MHz}$ & 499.26754(26) & 501.2 & $495.91763(15)$ & 498.29920(15) \\
\hline$P_{\mathrm{a}} / \mathrm{uA} \AA^{2}$ & $576.95262(70)$ & 709.6 & $580.46015(39)$ & $578.70743(42)$ \\
\hline$P_{\mathrm{b}} / \mathrm{u} \AA^{2}$ & $435.28825(70$ & 575.5 & $438.61838(39)$ & $435.50052(42)$ \\
\hline$P_{\mathrm{c}} / \mathrm{u} \AA^{2}$ & $378.98270(70)$ & 214.8 & $388.07669(39$ & $398.29777(42)$ \\
\hline$\Delta_{\mathrm{\jmath}} / \mathrm{kHz}$ & $0.0339(32)$ & 0.028 & [0.0339] & [0.0339] \\
\hline$\Delta_{\mathrm{JK}} / \mathrm{kHz}$ & $0.390(13)$ & 0.233 & [0.390] & [0.390] \\
\hline$\Delta_{\mathrm{K}} / \mathrm{kHz}$ & $-0.336(11)$ & -0.193 & {$[-0.336]$} & {$[-0.336]$} \\
\hline$\delta_{\mathrm{J}} / \mathrm{kHz}$ & $0.0086(16)$ & 0.007 & [0.0086] & {$[0.0086]$} \\
\hline$\delta_{\mathrm{k}} / \mathrm{kHz}$ & $-0.326(17)$ & -0.153 & {$[-0.320]$} & {$[-0.320]$} \\
\hline$\sigma / \mathrm{kHz}$ & 4.6 & & 5.3 & 6.0 \\
\hline$n$ & 80 & & 52 & 55 \\
\hline
\end{tabular}


Table S7. Comparison of the $r_{\mathrm{s}}$ coordinates of the observed adducts $12 \mathrm{C} 4-\mathrm{w}, \mathbf{C l}-\mathbf{W I}$ and $\mathbf{C I V - W I}$, and $\mathbf{C I V}-\mathbf{W}_{\mathbf{2}}$ and comparison with the ab initio MP2/6-311++G(d,p) (ab) structures. Note that the $r_{\mathrm{s}}$ method only gives the absolute values of the coordinates so the ab initio results help to choose the signs of the $r_{\mathrm{s}}$ coordinates.

\begin{tabular}{|c|c|c|c|c|}
\hline 12C4-w & CI-WI & $a$ & $b$ & $c$ \\
\hline$\left|r_{\mathrm{s}}\right|$ & \multirow[t]{2}{*}{$\mathrm{C}_{2}$} & $0.6653(24)$ & $2.25294(71$ & $0.2885(59)$ \\
\hline$a b$ & & -0.605231 & 2.253219 & -0.33345 \\
\hline$\left|r_{\mathrm{s}}\right|$ & \multirow[t]{2}{*}{$\mathrm{C}_{3}$} & $0.9369(30)$ & $1.8715(15)$ & $0.7657(38)$ \\
\hline$a b$ & & 0.822368 & 1.946623 & -0.735328 \\
\hline$\left|r_{\mathrm{s}}\right|$ & \multirow[t]{2}{*}{$\mathrm{C}_{5}$} & $2.69779(65)$ & $0.8417(21)$ & $0.090 \mathrm{i}(19)^{*}$ \\
\hline$a b$ & & 2.711542 & 0.790314 & 0.146248 \\
\hline$\left|r_{\mathrm{s}}\right|$ & \multirow[t]{2}{*}{$\mathrm{C}_{6}$} & $2.45558(63)$ & $0.6250(24)$ & $0.3876(40)$ \\
\hline$a b$ & & 2.436163 & -0.698995 & 0.188782 \\
\hline$\left|r_{\mathrm{s}}\right|$ & \multirow[t]{2}{*}{$\mathrm{C}_{8}$} & $0.9951(16)$ & $2.22271(74)$ & $0.7165(23)$ \\
\hline$a b$ & & 0.901968 & -2.247693 & -0.778877 \\
\hline$\left|r_{\mathrm{s}}\right|$ & \multirow[t]{2}{*}{$\mathrm{C}_{9}$} & $0.4636(33)$ & $1.99875(77)$ & $0.2263(68)$ \\
\hline$a b$ & & -0.503738 & -1.970667 & -0.286989 \\
\hline$\left|r_{\mathrm{s}}\right|$ & \multirow[t]{2}{*}{$\mathrm{C}_{11}$} & $1.5402(10)$ & $0.8208(18)$ & $1.5160(10)$ \\
\hline$a b$ & & -1.559032 & -0.780504 & 1.492834 \\
\hline$\left|r_{\mathrm{s}}\right|$ & \multirow[t]{2}{*}{$\mathrm{C}_{12}$} & $1.3094(12)$ & $0.6622(24)$ & $1.4317(11)$ \\
\hline$a b$ & & -1.323771 & 0.712641 & 1.366508 \\
\hline$\left|r_{\mathrm{s}}\right|$ & \multirow[t]{2}{*}{$\mathrm{O}_{\mathrm{w}}$} & $3.46836(43)$ & $0.18977(49)$ & $1.42490(11)$ \\
\hline$a b$ & & -3.521656 & -0.109814 & -1.285711 \\
\hline \multicolumn{5}{|c|}{ 12C4-w B - CIV-WI } \\
\hline$\left|r_{s}\right|$ & \multirow[t]{2}{*}{$\mathrm{O}_{\mathrm{w}}$} & $0.1840(82)$ & $0.4426(34)$ & $2.58066(59)$ \\
\hline$a b$ & & 0.171094 & -0.340684 & 2.537266 \\
\hline \multicolumn{5}{|l|}{ CIV-W } \\
\hline$\left|r_{\mathrm{s}}\right|$ & \multirow[t]{3}{*}{$\mathrm{O}_{\mathrm{w}}(1)$} & $1.2829(11)$ & $1.2005(13)$ & $2.22195(68)$ \\
\hline$r_{\mathrm{s}}$ with sigr & & $1.2829(11)$ & $-1.2005(13)$ & $2.22195(68)$ \\
\hline$a b$ & & 1.206376 & -1.452656 & 2.084067 \\
\hline$\left|r_{s}\right|$ & \multirow[t]{5}{*}{$\mathrm{O}_{w}(2)$} & $0.8924(17)$ & $0.2667(56)$ & $3.13869(48)$ \\
\hline$r_{\mathrm{s}}$ with sigr & & $-0.8924(17)$ & $0.2667(56)$ & $3.13869(48)$ \\
\hline$a b$ & & -1.036065 & -0.14913 & 3.022259 \\
\hline$r_{\mathrm{s}}\left(\mathrm{O}_{\mathrm{w}}(1) \cdots\right.$ & & $2.7794(35)$ & & \\
\hline$r_{\mathrm{e}}\left(\mathrm{O}_{\mathrm{w}}(1) \cdots\right.$ & & 2.7570 & & \\
\hline
\end{tabular}

${ }^{\mathrm{a} S e e}$ text. 
Table S8. $r_{0}$ structure of the observed adduct 12C4-w, conformer Cl-WI. The parameters fixed are given in squared brackets. In order to determine some structural parameters of the ring, they were set as if the $S_{4}$ symmetry were conserved in the cluster. The initial values for these parameters and the parameters associated to the methylene hydrogen atoms were taken as an average of the ab initio values. The $r_{0}$ structure of water (M. D. Harmony, V. W. Laurie, R. L. Kuczkowski, R. H. Schwendeman, D. A. Ramsay, F. J. Lovas, W. J. Lafferty, A. G. Maki, J. Phys. Chem. Ref. Data 1979, 8, 619.) was kept fixed in the fit.

\begin{tabular}{|c|c|c|c|}
\hline Parameter $^{a}$ & $r_{0}$ & Parameter $^{\mathrm{a}}$ & \\
\hline$r\left(\mathrm{O}_{1}-\mathrm{C}_{2}\right) / \AA$ & $1.431(23)$ & $\angle \mathrm{H}_{16} \mathrm{C}_{3} \mathrm{C}_{2} /^{\circ}$ & [109.53] \\
\hline$r\left(\mathrm{C}_{2}-\mathrm{C}_{3}\right) / \AA$ & $1.524(68)$ & $\angle \mathrm{H}_{13} \mathrm{C}_{2} \mathrm{O}_{1} \mathrm{C}_{12} /^{\circ}$ & {$[-147.14]$} \\
\hline$\angle \mathrm{C}_{3} \mathrm{C}_{2} \mathrm{O}_{1}{ }^{\circ}$ & 111.36(84) & $\angle \mathrm{H}_{14} \mathrm{C}_{2} \mathrm{O}_{1} \mathrm{C}_{12} /^{\circ}$ & {$[-28.94]$} \\
\hline$\angle \mathrm{O}_{4} \mathrm{C}_{3} \mathrm{C}_{2} /^{\circ}$ & $108.3(23)$ & $\angle \mathrm{H}_{15} \mathrm{C}_{3} \mathrm{C}_{2} \mathrm{O}_{1} /^{\circ}$ & [49.03] \\
\hline$\angle \mathrm{C}_{5} \mathrm{O}_{4} \mathrm{C}_{3} /^{\circ}$ & $114.2(34)$ & $\angle \mathrm{H}_{16} \mathrm{C}_{3} \mathrm{C}_{2} \mathrm{O}_{1} /^{\circ}$ & [168.3] \\
\hline$\angle \mathrm{O}_{4} \mathrm{C}_{3} \mathrm{C}_{2} \mathrm{C}_{3} /^{\circ}$ & [-70.9] & & \\
\hline$\angle \mathrm{C}_{5} \mathrm{O}_{4} \mathrm{C}_{3} \mathrm{C}_{2} /^{\circ}$ & [158.1] & $r\left(\mathrm{O}_{\mathrm{W}}-\mathrm{O}_{1}\right) / \AA$ & $2.808(57)$ \\
\hline$\angle \mathrm{C}_{6} \mathrm{C}_{5} \mathrm{O}_{4} \mathrm{C}_{3} /^{\circ}$ & {$[-94.77]$} & $\angle \mathrm{O}_{\mathrm{w}} \mathrm{O}_{1} \mathrm{C}_{2} /^{\circ}$ & $126.4(28)$ \\
\hline$r\left(\mathrm{H}_{13} \mathrm{C}_{2}\right) / \AA$ & [1.096] & $\angle \mathrm{O}_{\mathrm{w}} \mathrm{O}_{1} \mathrm{C}_{2} \mathrm{C}_{3} /^{\circ}$ & $-113.2(43)$ \\
\hline$r\left(\mathrm{H}_{14} \mathrm{C}_{2}\right) / \AA$ & [1.099] & $r\left(\mathrm{H}_{\mathrm{w}} \mathrm{O}_{\mathrm{w}}\right) / \AA$ & [0.965] \\
\hline$r\left(\mathrm{H}_{15} \mathrm{C}_{3}\right) / \AA$ & [1.094] & $\angle \mathrm{H}_{\mathrm{w}} \mathrm{O}_{\mathrm{w}} \mathrm{H}_{\mathrm{wn}} /^{\circ}$ & [104.8] \\
\hline$r\left(\mathrm{H}_{16} \mathrm{C}_{3}\right) / \AA$ & [1.102] & $\angle \mathrm{H}_{\mathrm{w}} \mathrm{O}_{\mathrm{w}} \mathrm{O}_{1} 1^{\circ}$ & [10.78] \\
\hline$\angle \mathrm{H}_{13} \mathrm{C}_{2} \mathrm{O}_{1}{ }^{\circ}$ & [106.79] & $\angle \mathrm{H}_{\mathrm{w}} \mathrm{O}_{\mathrm{w}} \mathrm{O}_{1} \mathrm{C}_{2} /^{\circ}$ & [-18.903] \\
\hline$\angle \mathrm{H}_{14} \mathrm{C}_{2} \mathrm{O}_{1}{ }^{\circ}$ & [110.81] & $\angle \mathrm{H}_{\mathrm{wn}} \mathrm{O}_{\mathrm{w}} \mathrm{H}_{\mathrm{w}} \mathrm{O}_{1} /^{\circ}$ & [168.49] \\
\hline$\angle \mathrm{H}_{15} \mathrm{C}_{3} \mathrm{C}_{2} /^{\circ}$ & [108.73] & & \\
\hline
\end{tabular}

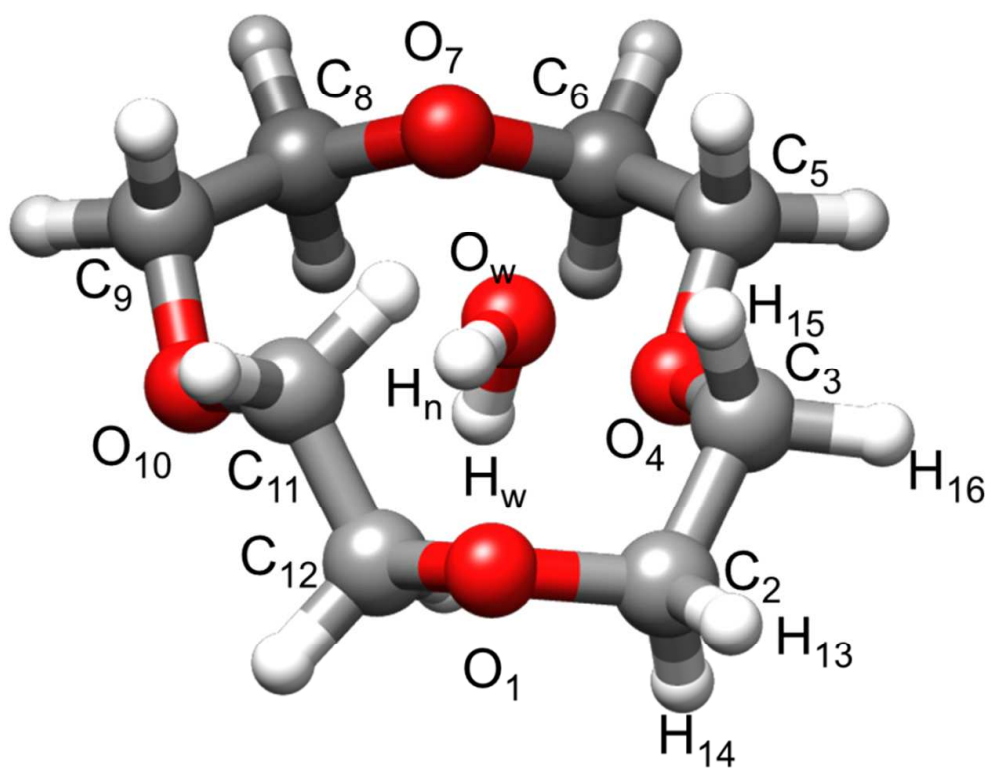


Figure S5. Structures of the 12-crown-4 ether $\cdots\left(\mathrm{H}_{2} \mathrm{O}\right)$ forms observed in this work. On the left the figures show the coincidence of $r_{s}$ oxygen positions with those predicted from ab initio calculations. On the right, some labeling and structural data are given. The distances shown for the 12C4-w A (C1-wa) rotamer correspond to the $\mathrm{r}_{0}$ structure. For the other forms the ab initio distances are given.

\section{C4-w, Cl-WI}
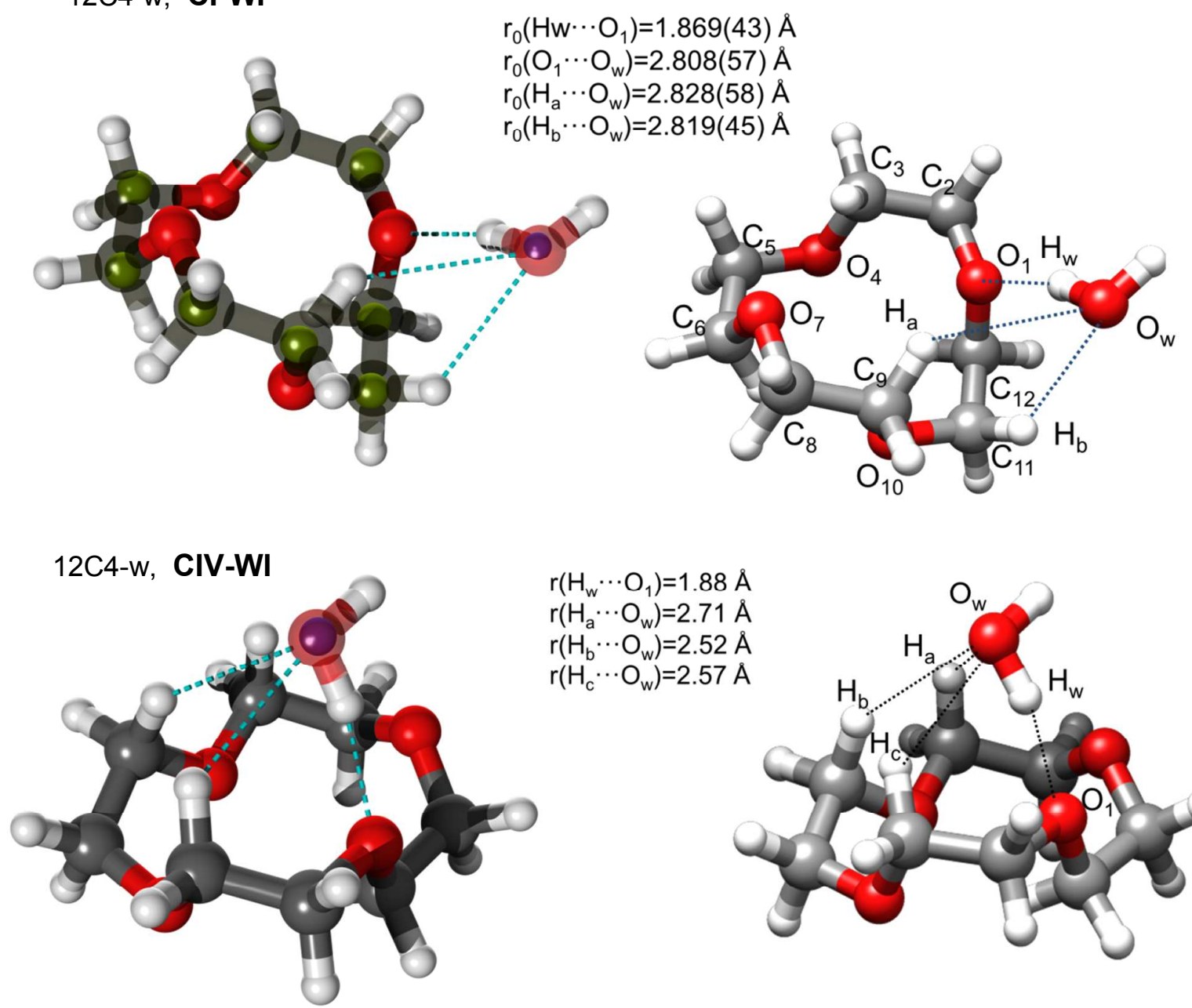

$$
\begin{aligned}
& r\left(H_{w} \cdots O_{1}\right)=1.88 \AA \\
& r\left(H_{a} \cdots O_{w}\right)=2.71 \AA \\
& r\left(H_{b} \cdots O_{w}\right)=2.52 \AA \\
& r\left(H_{c} \cdots O_{w}\right)=2.57 \AA
\end{aligned}
$$

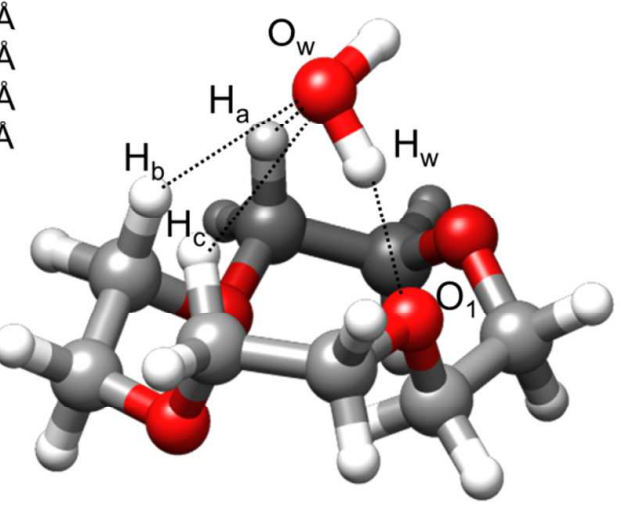

12C4-w, CIV-WII

$$
\begin{aligned}
& r\left(H_{w} \cdots O_{2}\right)=1.88 \AA \\
& r\left(H_{a} \cdots O_{w}\right)=2.58 \AA \\
& r\left(H_{b} \cdots O_{w}\right)=2.52 \AA \\
& r\left(H_{c} \cdots O_{w}\right)=2.71 \AA
\end{aligned}
$$

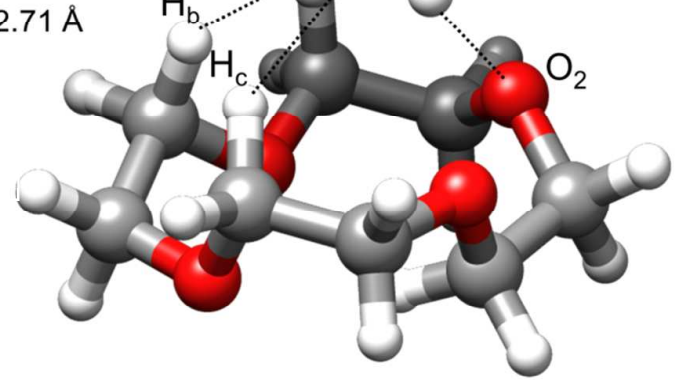


Figure S6. Structures of the 12-crown-4 ether $\cdots\left(\mathrm{H}_{2} \mathrm{O}\right)_{2}$ cluster, conformer $\mathbf{C I V}-\mathbf{W}_{\mathbf{2}}$, observed in this work. On the left, the coincidence of $r_{\mathrm{s}}$ oxygen positions with those predicted from ab initio calculations is shown. On the right some structural data are given. The distances given in the figure correspond to ab initio prediction. The $r_{\mathrm{s}} \mathrm{O}_{\mathrm{w} 1} \cdots$ $\mathrm{O}_{\mathrm{w} 1}$ distance is also compared to the ab initio value.

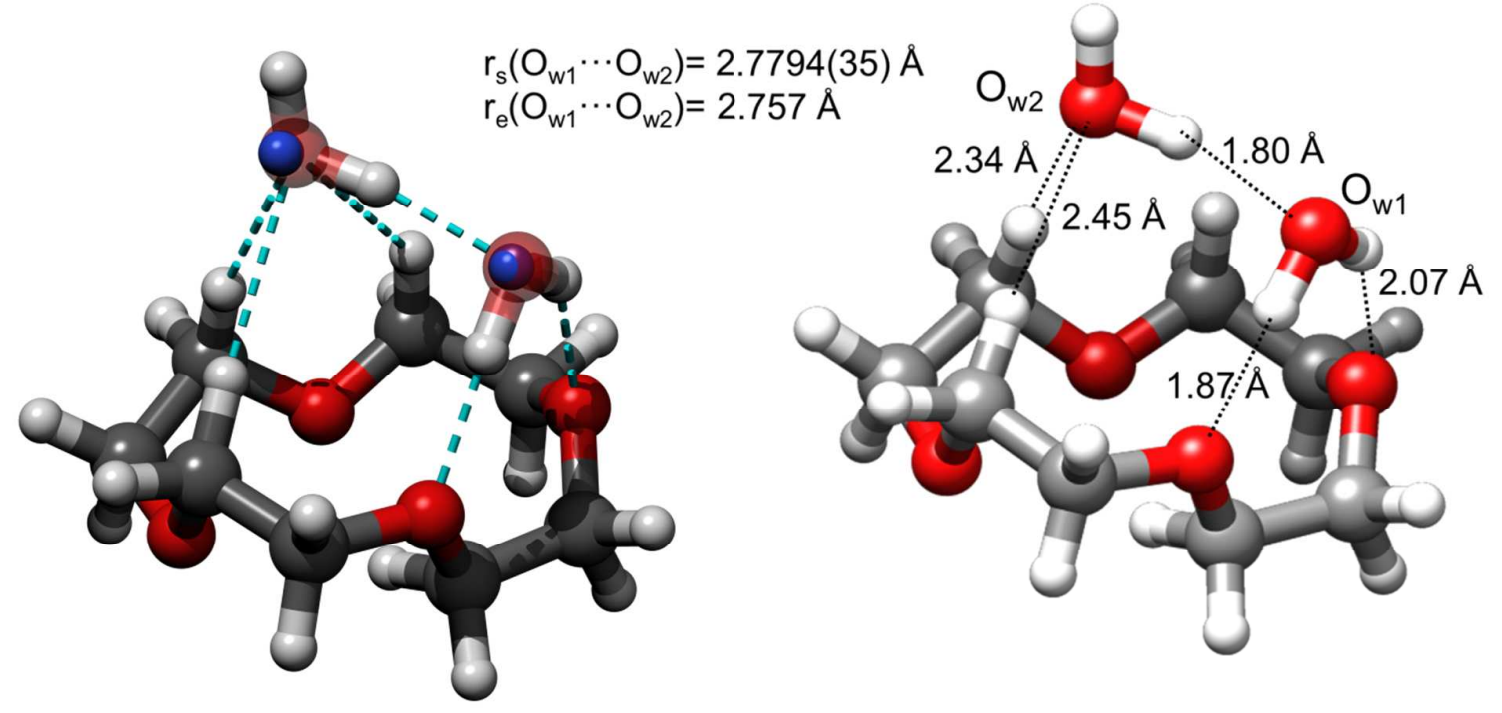


Table S9. Details of the calculations performed to identify the structure of the $\mathbf{C I V}-\mathbf{W}_{\mathbf{2}}$ rotamer from the parent species rotational constants and the $r_{\mathrm{s}}$ coordinates of the water oxygen atoms (see Table S7). A discussion of these results is given in next page.

\begin{tabular}{c|cccccccc|c} 
& $\mathrm{O}_{1} / \mathrm{O}_{2}$ & $\mathrm{O}_{1} / \mathrm{O}_{2}$ & $\mathrm{O}_{1} / \mathrm{O}_{2}$ & $\mathrm{O}_{1} / \mathrm{O}_{2}$ & $\mathrm{O}_{1} / \mathrm{O}_{2}$ & $\mathrm{O}_{1} / \mathrm{O}_{2}$ & $\mathrm{O}_{1} / \mathrm{O}_{2}$ & $\mathrm{O}_{1} / \mathrm{O}_{2}$ & CIV \\
\hline Rel. sign $a$ & $+/+$ & $+/+$ & $+/+$ & $+/-$ & $+/+$ & $+/-$ & $+/-$ & $+/-$ & \\
Rel. sign $b$ & $+/+$ & $+/+$ & $+/-$ & $+/+$ & $+/-$ & $+/+$ & $+/-$ & $+/-$ & \\
Rel. sign $c$ & $+/+$ & $+/-$ & $+/+$ & $+/+$ & $+/-$ & $+/-$ & $+/+$ & $+/-$ & \\
$r_{\mathrm{OO}} / \AA^{2}$ & 1.37 & 5.46 & 1.77 & 2.54 & 5.57 & 5.86 & 2.80 & 5.97 & \\
$A / \mathrm{MHz}$ & 1173.18 & 1002.89 & 1165.36 & 1100.86 & 989.17 & 1030.91 & 1103.16 & 1026.80 & 1129.1 \\
$B / \mathrm{MHz}$ & 889.57 & 785.42 & 871.56 & 871.00 & 802.66 & 787.39 & 849.09 & 799.07 & 855.7 \\
$C / \mathrm{MHz}$ & 517.18 & 542.55 & 522.48 & 529.94 & 535.91 & 524.44 & 535.16 & 517.92 & 536.1 \\
$P_{\mathrm{cc}} / \mathrm{u} \AA^{2}$ & 10.85 & 107.94 & 23.13 & 42.83 & 98.76 & 84.21 & 54.49 & 74.43 & 47.72
\end{tabular}

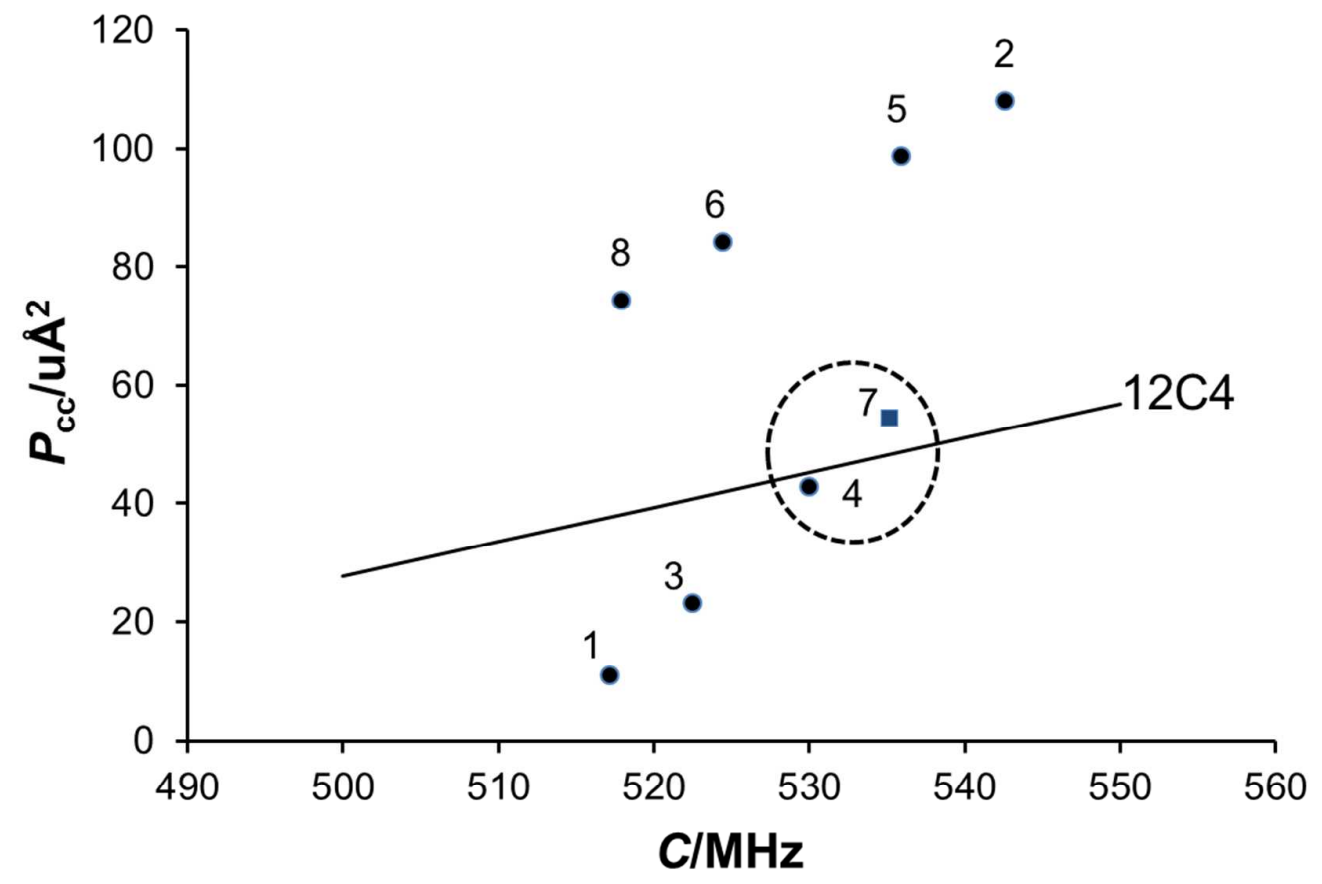




\section{Discussion of the results of Table $\mathbf{5 9}$}

Since we only had the oxygen atom coordinates we have assumed that the oxygen atom is close to the center of mass of water, and considered all the mass of water being at the oxygen position. We consider all possible sign combinations and calculate the possible oxygen atom locations in each case testing the $0 \cdots 0$ distance to have a reasonable value. The Table collects the eight possible relative sign combinations for these coordinates and the calculated $r_{0 o}$ distances in each case. From these distances combinations 1, 3 and perhaps 4 give distances that seem to be very short if both water molecules are on the same side of the ring plane. From the distances, combination 7 seems to belong to a plausible form with two water molecules on the same side of the $12 \mathrm{C} 4$ ring, and combinations 2, 5, 6 and 8 to possible structures with water on both sides of the 12C4 ring. The coordinates have been assumed to be the position of the centers of mass of both water molecules (the $\mathrm{z}$ coordinate of $\mathrm{O}$ atom in water is ca. $0.066 \AA^{2}$ ) to subtract the contributions of the water molecules to the parent species moments of inertia and to calculate the hypothetical rotational constants of bare $12 \mathrm{C} 4$ in the cluster given in the table. The method was tested with previously identified heterodimers (see Table S9). A $P_{\mathrm{cc}}$ vs $C$ plot of the calculated constants (see figure below) reveals that only combinations 4 and 7 lie along the correlation line calculated from the ab initio constants of the different 12C4 conformers (see figure 1). Finally, only combination 7 has a reasonable $r(\mathrm{O} \cdots \mathrm{O})$ distance of $2.779 \AA$ giving a set of approximate rotational constants $A=1103 \mathrm{MHz}, B=849 \mathrm{MHz}$ and $C=535 \mathrm{MHz}$ that allow the identification of conformer CIV (see Table S1 and figure S1) as the structure of 12C4 in the complex. This allows a tentative identification of $12 \mathrm{C} 4$ form as CIV (see table S1). The method used allows also the calculation of the coordinates of the water centers of mass in the principal inertial axis system of bare 12C4. Using these coordinates and CIV conformation to start an ab initio optimization, convergence criteria were met for the structure shown in Figure S6. The calculated rotational constants (see Table 1) and the calculated oxygen atom positions (see Table S7) confirm the identification of the structure of the observed species. 
Table S10. Results of the calculations done on the observed species of the $12 \mathrm{C} 4$ water cluster to test the "drying" procedure used to identify the12C4-w structure. $^{a}$.

a This procedure uses with the $r_{s}$ coordinates of water oxygen and the parent species rotational constants. The hypothetical rotational constants

\begin{tabular}{|c|c|c|c|c|c|c|c|c|c|c|c|}
\hline & \multicolumn{3}{|c|}{ 12C4-w CI-WI } & \multicolumn{3}{|c|}{ 12C4-w CIV-WI } & \multicolumn{2}{|c|}{ 12C4-w CIV-WII } & \multicolumn{3}{|c|}{ CIV-W 2} \\
\hline $\mathrm{A} / \mathrm{MHz}$ & 1001.51 & 998.44 & 994.34 & 1132.98 & 1150.36 & 1129.1 & 1092.88 & 1129.1 & 1103.16 & 1126.12 & 1129.1 \\
\hline $\mathrm{B} / \mathrm{MHz}$ & 960.55 & 988.16 & 993.82 & 850.28 & 849.79 & 855.7 & 879.54 & 855.7 & 849.09 & 855.84 & 855.7 \\
\hline $\mathrm{C} / \mathrm{MHz}$ & 600.38 & 612.34 & 613.49 & 536.31 & 541.92 & 536.1 & 538.46 & 536.1 & 535.16 & 539.42 & 536.1 \\
\hline
\end{tabular}

of bare $12 \mathrm{C} 4$ in the cluster given in columns (1) have been calculated by subtracting the contributions of the water molecules to the parent species moments of inertia assuming all mass of water is at the oxygen atom position. This means to assume that the $r_{s}$ coordinates are nearly coincident to the position of the center of mass of water (the $z$ coordinate of $O$ atom in water is ca. $0.066 \AA^{2}$ ). The values on columns (2) have been exactly calculated using the ab initio structures and rotational constants of the identified conformers. The values on column (3) correspond to optimization of the structure of bare $12 \mathrm{C} 4$ corresponding to column (2). It is interesting to note that conformers CIV-WI and CIV-WI land CIVW2 can also be calculated starting form conformer CII instead of CIV 
Figure S7. On the left one of the possible energy paths between conformers CII and CIV of 12C4 is illustrated where a transition configuration with an ab initio calculated energy of $2 \mathrm{kJmol}^{-1}$ is shown. The presence of water alters the potential energy surface overcoming this small barrier so the clusters of $12 \mathrm{C} 4$ with water observed in this work (on the right) are formed from either CII or CIV conformers. A dotted line shows the part of CII form which is altered in the process opening the ring to maximize the interactions between $12 \mathrm{C} 4$ and water. The qualitative description of the third torsional angle changes from CII (+) to CIV (0) (see Table S1 and figure S1). As it can be seen in the clusters with one water molecule the three hydrogen atoms encircled are almost equidistant to the water oxygen atom allowing for three $\mathrm{C}-\mathrm{H} \cdots \mathrm{O}$ contacts.
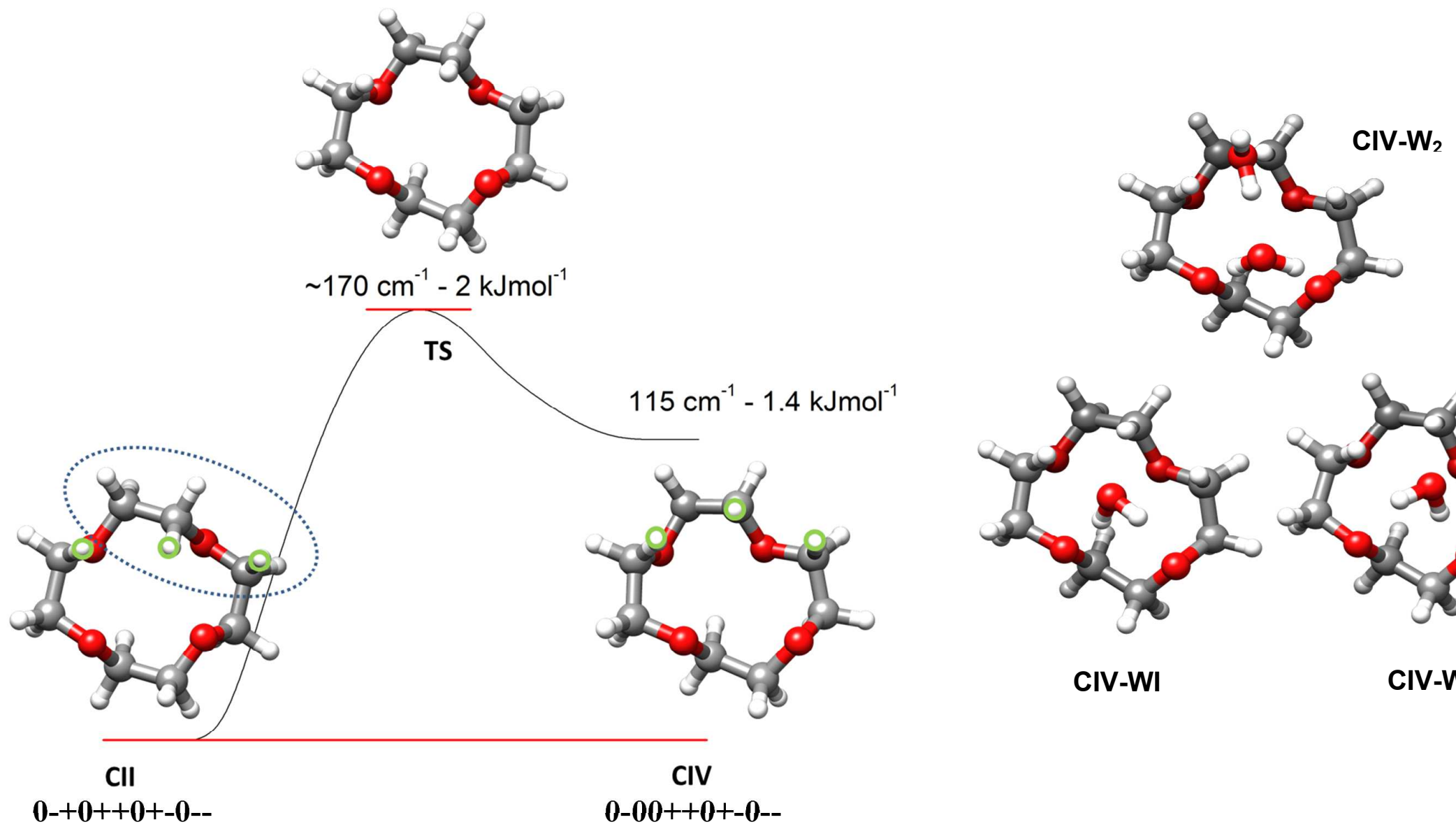

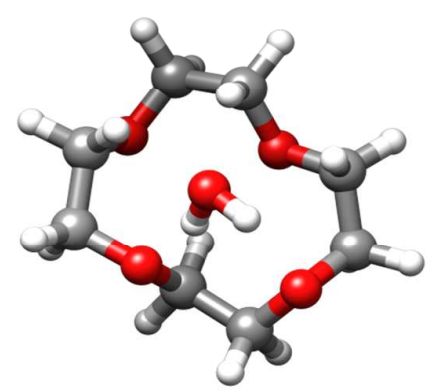

CIV-WI

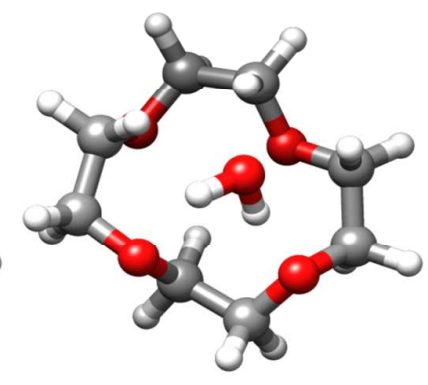

CIV-WII

$0-00++0+-0-$ 
Table S11. Observed rotational transitions and residuals (all the values in $\mathrm{MHz}$ ) for the parent species of the cluster $12 \mathrm{C} 4-\mathrm{W} \mathrm{Cl} \mathbf{C W I}$ in the ground vibrational state for transitions of the type $J^{\prime}, K_{a}^{\prime}, K_{c}^{\prime} \leftarrow J$ ", $K_{a}^{\prime \prime}, K_{c}^{\prime \prime}$

\begin{tabular}{|c|c|c|c|c|c|c|c|c|c|c|c|c|c|c|c|}
\hline & $K^{\prime}$ & $K^{\prime}$ & "l" & $k^{\prime \prime}$ & $K_{b}^{\prime \prime}$ & & i- & & & $K_{b}^{\prime}$ & l" & $K^{\prime \prime}$ & $K_{b}^{\prime \prime}$ & os. & S- \\
\hline 5 & 4 & 2 & 5 & 3 & 3 & 207 & -0.0 & 9 & 3 & 7 & 9 & 2 & 8 & & 001 \\
\hline 2 & 1 & 2 & 1 & 1 & 1 & 2 & & 0 & 1 & 7 & 8 & 0 & 8 & & 01 \\
\hline 5 & 2 & 4 & 5 & 1 & 5 & & & & 1 & 2 & 2 & . & 1 & & 004 \\
\hline 6 & 4 & 3 & 6 & 3 & 4 & 216 & -0 . & 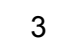 & 2 & 1 & 2 & 2 & 0 & & \\
\hline 2 & 0 & 2 & 1 & 0 & 1 & & & 8 & 2 & 7 & 8 & 1 & 8 & & \\
\hline 6 & 3 & 4 & 6 & 2 & 5 & 218 & -0.0 & 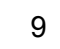 & 7 & 2 & 9 & 6 & 3 & & 003 \\
\hline$r$ & 5 & 2 & 7 & 4 & 3 & $22 c$ & & 9 & 7 & 3 & 9 & 6 & 4 & & 002 \\
\hline 2 & 1 & 2 & 1 & 0 & 1 & 230 & 0 & 8 & 7 & 1 & 8 & 6 & 2 & & 04 \\
\hline$r$ & 2 & 5 & 7 & 1 & 6 & 231 & 0.008 & 10 & 3 & 8 & 10 & 2 & 9 & & 002 \\
\hline 7 & 4 & 4 & 7 & 3 & 5 & 2338 & 0.000 & 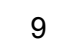 & 1 & 8 & 9 & 0 & 9 & 73 & -0.008 \\
\hline 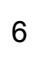 & 5 & 1 & 6 & 4 & 2 & 247 & 0.001 & - & 2 & 8 & 9 & 1 & 9 & & .000 \\
\hline 6 & 1 & 5 & 6 & 0 & 6 & 2534 & 0.004 & 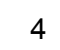 & 0 & 4 & 3 & 1 & 3 & 06 & -0.004 \\
\hline 7 & 3 & 5 & 7 & 2 & 6 & 256 & c & 两 & 0 & 4 & 3 & 0 & 3 & & 0.004 \\
\hline 6 & 5 & 2 & 6 & 4 & 3 & 257 & & 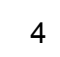 & 1 & 3 & 3 & 2 & 2 & & 05 \\
\hline 0 & 2 & 5 & 6 & 1 & 6 & 259 & & 3 & 2 & 1 & 2 & 1 & 1 & & \\
\hline 5 & 5 & 1 & 5 & 4 & 2 & & & 4 & 2 & 3 & 3 & 2 & 2 & & \\
\hline 8 & 4 & 5 & 8 & 3 & 6 & 260 & & 4 & 1 & 3 & 3 & 1 & 2 & & \\
\hline 8 & 5 & 4 & 8 & 4 & 5 & & & & 2 & 1 & 2 & . & 2 & & \\
\hline 2 & 1 & 1 & 1 & 0 & 1 & $27 €$ & -0 & 4 & 2 & 2 & 3 & 2 & 1 & & 22 \\
\hline 9 & 5 & 5 & 9 & 4 & 6 & & & & 3 & 1 & 2 & 2 & 0 & & \\
\hline 3 & 1 & 2 & 2 & 2 & 1 & 28 & & 3 & 3 & 0 & 2 & 2 & 0 & & \\
\hline 8 & 2 & 6 & 8 & 1 & 7 & 288 & & & 3 & 1 & 2 & 2 & 1 & & \\
\hline$y$ & 4 & 6 & 9 & 3 & 7 & & -0 . & 3 & 3 & 0 & 2 & 2 & 1 & & \\
\hline 8 & 3 & 6 & 8 & 2 & 7 & 299 & & 4 & 2 & 3 & 3 & 1 & 2 & & \\
\hline 8 & 6 & 2 & 8 & 5 & 3 & 299 & & & 0 & 5 & 4 & 1 & 4 & & \\
\hline 3 & 0 & 3 & 2 & 1 & 2 & 303 & & 5 & 1 & 5 & 4 & 1 & 4 & & \\
\hline 2 & 2 & 1 & 1 & 1 & 0 & 306 & & & 0 & 5 & 4 & 0 & 4 & & \\
\hline 9 & 6 & 4 & 9 & 5 & 5 & & & 5 & 1 & 5 & 4 & 0 & 4 & & 01 \\
\hline 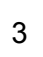 & 1 & 3 & 2 & 1 & 2 & 3091 & -0. & 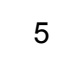 & 1 & 4 & 4 & 2 & 3 & & -0.001 \\
\hline 8 & 6 & 3 & 8 & 5 & 4 & & & 6 & 3 & 3 & 5 & 4 & 2 & & \\
\hline 7 & 6 & 1 & 7 & 5 & 2 & & & 5 & 2 & 4 & 4 & 2 & 3 & & 0.005 \\
\hline 2 & 2 & 0 & 1 & 1 & 0 & & & . & 2 & 2 & 3 & 1 & 2 & & \\
\hline 3 & 0 & 3 & 2 & 0 & 2 & & & 7 & 3 & 5 & 6 & 4 & 2 & & 12 \\
\hline 6 & 6 & 1 & 6 & 5 & 2 & & & & 1 & 4 & 4 & 1 & 3 & 56 & \\
\hline 2 & 2 & 1 & 1 & 1 & 1 & & & 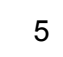 & 3 & 3 & 4 & 3 & 2 & & -0.004 \\
\hline 3 & 1 & 3 & 2 & 0 & 2 & 3218.878 & -0.003 & 5 & 4 & 2 & 4 & 4 & 1 & 5707.389 & 0.000 \\
\hline 3 & 2 & 2 & 2 & 2 & 1 & & & 5 & 4 & 1 & 4 & 4 & 0 & & 0.003 \\
\hline 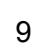 & 2 & 7 & 9 & 1 & 8 & 3413.372 & 0.002 & $\checkmark$ & 2 & 4 & 4 & 1 & 0 & 5756.591 & 0.003 \\
\hline
\end{tabular}


Table S11. (continued)

$\begin{array}{llllllllllllll}J^{\prime} & K_{a}^{\prime} & K_{a}^{\prime} & J & K^{\prime \prime} & K_{b}^{\prime \prime} & \text { obs. obs-calc } & J^{\prime} & K_{a}^{\prime} & K_{b}^{\prime} & J " & K_{a}^{\prime \prime} & K_{b}^{\prime \prime} & \text { obs. obs-calc }\end{array}$

\begin{tabular}{|c|c|c|c|c|c|c|c|c|c|c|c|c|c|c|c|}
\hline & 2 & 3 & 3 & 1 & 3 & 5815.596 & 0.010 & 7 & 0 & 7 & 6 & 1 & 6 & 6988.333 & 0.003 \\
\hline & 3 & 2 & 3 & 2 & & 5843.232 & 0.002 & 7 & 1 & 7 & 6 & 1 & 0 & 6988.84 & .004 \\
\hline & 3 & 2 & 4 & 3 & 1 & 5882.667 & -0.001 & 7 & 0 & . & 6 & 0 & 6 & 0 & .004 \\
\hline & 3 & 1 & 3 & 2 & & 5930.839 & 0.000 & 7 & 1 & 7 & 6 & 0 & 6 & 6990.637 & 0.005 \\
\hline & 2 & 3 & 4 & 2 & 2 & 5958.545 & 0.001 & 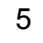 & 3 & 2 & 1 & 2 & 2 & 7040.572 & 0.002 \\
\hline 6 & 2 & 4 & 5 & 3 & 2 & 5982.252 & -0.012 & 7 & 2 & 5 & 6 & 3 & 3 & 6900.535 & -0.010 \\
\hline & 0 & 6 & 5 & 1 & 5 & 6021.738 & -0.001 & 6 & 4 & 2 & 5 & 4 & 1 & 6948.951 & 0.007 \\
\hline 6 & 1 & 6 & 5 & 1 & 5 & 6023.534 & 0.000 & 6 & 2 & 4 & 5 & 2 & 3 & 7064.287 & -0.002 \\
\hline 6 & 0 & 6 & 5 & 0 & 5 & 6027.824 & 0.001 & 5 & 1 & 4 & 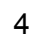 & 0 & 4 & 7074.613 & -0.005 \\
\hline 6 & 1 & 6 & 5 & 0 & 5 & 6029.617 & -0.002 & 6 & 3 & 3 & 5 & 3 & 2 & 7155 & -0.001 \\
\hline 4 & 3 & 2 & 3 & 2 & 2 & 6085.614 & -0.002 & 5 & 2 & 4 & 4 & 1 & 4 & 7197.969 & -0.001 \\
\hline 2 & 3 & 1 & 3 & 2 & 2 & 6173.228 & .004 & $\mathrm{~J}$ & 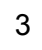 & 3 & 4 & 2 & 3 & & -0.003 \\
\hline 6 & 2 & 4 & 5 & 3 & 3 & 6275.351 & 0.002 & 7 & 1 & 6 & 6 & 2 & 5 & 7437.479 & 0.000 \\
\hline 6 & 1 & 5 & 5 & 2 & 4 & 6414.025 & 0.002 & $r$ & 2 & 6 & 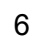 & 2 & 5 & 745 & .002 \\
\hline 6 & 2 & 5 & 5 & 2 & 4 & 6471.772 & -0.002 & 7 & 1 & 6 & 6 & 1 & 5 & 7495.234 & 0.003 \\
\hline 8 & 4 & 5 & 7 & 5 & 2 & 6519.486 & .013 & 7 & 2 & 6 & 6 & 1 & 5 & 751 & 0.005 \\
\hline 6 & 1 & 5 & 5 & 1 & 4 & 6556.635 & -0.00 & 6 & 3 & 4 & 5 & ? & 3 & & -0.001 \\
\hline 4 & 4 & 1 & 3 & 3 & 0 & 6576.440 & -0.00 & 7 & 2 & 5 & 6 & 3 & 4 & 7573 & -0.001 \\
\hline 4 & 4 & 0 & 3 & 3 & 0 & 657 & 0. & & 0 & 2 & 4 & 2 & 3 & 7632 & -0.001 \\
\hline 4 & 4 & 1 & 3 & 3 & 1 & 6590.150 & -0.002 & 5 & 4 & 2 & 4 & 3 & 1 & 76 & -0.005 \\
\hline 2 & 4 & 0 & 3 & 3 & 1 & 659 & 0.000 & & 4 & 1 & 4 & 3 & 1 & & 0.007 \\
\hline 6 & 2 & 5 & 5 & 1 & 4 & 6614.387 & -0.001 & 5 & 4 & 2 & 4 & 3 & 2 & 774 & 0.000 \\
\hline 4 & 3 & 1 & 3 & 1 & 2 & 6661.772 & 0.007 & 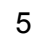 & 4 & 1 & 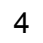 & 3 & 2 & 7771.122 & 0.002 \\
\hline 5 & 3 & 3 & 4 & 2 & 2 & 6747.489 & 0.005 & 7 & 3 & 5 & 6 & 3 & 4 & 7838 & 0.002 \\
\hline 6 & 3 & 4 & 5 & 3 & 3 & 6775.728 & -0.008 & 8 & 0 & 8 & $t$ & 1 & 7 & 7953.045 & -0.008 \\
\hline 5 & 2 & 3 & 4 & 1 & 3 & 6844.241 & 0.003 & 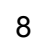 & 1 & 8 & 7 & 1 & 7 & 7953.185 & -0.006 \\
\hline 6 & 5 & 2 & 5 & 5 & 1 & 6848.369 & -0.003 & 8 & 0 & 8 & 7 & 0 & 7 & 7953.552 & -0.007 \\
\hline 6 & 5 & 1 & 5 & 5 & 0 & 6853.165 & -0.009 & 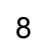 & 1 & 8 & 7 & 0 & 7 & 7953.695 & -0.002 \\
\hline & 4 & 3 & 5 & 4 & 2 & $086 \% .323$ & & & 6 & 2 & 0 & 6 & 1 & & 0.006 \\
\hline & 3 & 4 & 6 & 4 & 3 & 6888.376 & -0.008 & 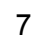 & 6 & 1 & 6 & 6 & 0 & 7985.843 & -0.003 \\
\hline
\end{tabular}


Table S12. Observed rotational transitions and residuals (all the values in $\mathrm{MHz}$ ) for the ${ }^{18} \mathrm{O}$ and ${ }^{13} \mathrm{C}_{11}$ species of the cluster $12 \mathrm{C} 4-\mathrm{W} \mathrm{Cl}-\mathbf{W I}$ in the ground vibrational state for transitions of the type $J^{\prime}, K_{a}^{\prime}, K_{c}^{\prime} \leftarrow J^{\prime \prime}, K^{\prime \prime}, K_{c}^{\prime \prime}$.

\begin{tabular}{|c|c|c|c|c|c|c|c|c|c|c|c|c|c|c|c|}
\hline \multicolumn{8}{|c|}{$12 \mathrm{C} 4-\mathrm{H}_{2}{ }^{18} \mathrm{O} A$} & \multicolumn{8}{|c|}{${ }^{13} \mathrm{C}_{11} 12 \mathrm{C} 4-\mathrm{H}_{2} \mathrm{O} A$} \\
\hline J' & $K_{a}^{\prime}$ & $K_{a}^{\prime}$ & J" & $K_{a}^{\prime \prime}$ & $K_{b}^{\prime \prime}$ & obs. & obs-calc & $J^{\prime}$ & $K_{a}^{\prime}$ & $K_{b}^{\prime}$ & J" & $K_{a}^{\prime \prime}$ & $K_{b}^{\prime \prime}$ & obs. & obs-calc \\
\hline 10 & 2 & 8 & 10 & 1 & 9 & 3766.841 & 0.004 & 8 & 0 & 8 & 7 & 1 & 7 & 7927.903 & 0.009 \\
\hline 4 & 1 & 4 & 3 & 0 & 3 & 4051.213 & 0.014 & 7 & 2 & 6 & 6 & 1 & 5 & 7489.234 & -0.002 \\
\hline 3 & 3 & 1 & 2 & 2 & 0 & 4790.949 & 0.008 & 7 & 1 & 6 & 6 & 2 & 5 & 7408.664 & 0.004 \\
\hline 3 & 3 & 0 & 2 & 2 & 0 & 4801.270 & -0.006 & 7 & 1 & 7 & 6 & 0 & 6 & 6968.334 & -0.002 \\
\hline 5 & 0 & 5 & 4 & 0 & 4 & 4955.498 & -0.003 & 7 & 1 & 7 & 6 & 1 & 6 & 6966.475 & -0.001 \\
\hline 5 & 1 & 5 & 4 & 0 & 4 & 4964.558 & 0.007 & 7 & 0 & 7 & 6 & 1 & 6 & 6965.955 & 0.008 \\
\hline 6 & 0 & 6 & 5 & 1 & 5 & 5882.852 & -0.012 & 5 & 3 & 3 & 4 & 2 & 2 & 6719.924 & 0.007 \\
\hline 6 & 1 & 6 & 5 & 1 & 5 & 5885.780 & -0.004 & 6 & 2 & 5 & 5 & 1 & 4 & 6591.173 & -0.003 \\
\hline 6 & 0 & 6 & 5 & 0 & 5 & 5891.913 & -0.002 & 6 & 1 & 5 & 5 & 2 & 4 & 6387.075 & -0.014 \\
\hline 6 & 1 & 6 & 5 & 0 & 5 & 5894.835 & 0.001 & 6 & 2 & 4 & 5 & 3 & 3 & 6238.793 & 0.002 \\
\hline 8 & 4 & 5 & 7 & 5 & 2 & 6161.063 & -0.005 & 6 & 1 & 6 & 5 & 0 & 5 & 6010.191 & -0.011 \\
\hline 4 & 4 & 1 & 3 & 3 & 0 & 6521.388 & 0.001 & 6 & 0 & 6 & 5 & 1 & 5 & 6002.090 & 0.003 \\
\hline 4 & 4 & 0 & 3 & 3 & 1 & 6533.584 & -0.008 & 4 & 3 & 2 & 3 & 2 & 1 & 5816.968 & -0.002 \\
\hline 7 & 0 & 7 & 6 & 1 & 6 & 6829.009 & -0.008 & 5 & 2 & 4 & 4 & 1 & 3 & 5736.115 & -0.006 \\
\hline 7 & 1 & 7 & 6 & 1 & 6 & 6829.911 & -0.004 & 5 & 1 & 4 & 4 & 2 & 3 & 5295.302 & -0.008 \\
\hline 7 & 0 & 7 & 6 & 0 & 6 & 6831.934 & -0.001 & 5 & 1 & 5 & 4 & 0 & 4 & 5058.264 & -0.004 \\
\hline 7 & 1 & 7 & 6 & 0 & 6 & 6832.836 & 0.002 & 5 & 0 & 5 & 4 & 0 & 4 & 5052.017 & 0.003 \\
\hline 7 & 1 & 6 & 6 & 2 & 5 & 7247.409 & 0.003 & 5 & 1 & 5 & 4 & 1 & 4 & 5038.644 & 0.011 \\
\hline 7 & 2 & 6 & 6 & 1 & 5 & 7363.287 & 0.009 & 3 & 2 & 1 & 2 & 1 & 2 & 4696.919 & 0.005 \\
\hline 5 & 4 & 2 & 4 & 3 & 1 & 7581.666 & -0.007 & 4 & 1 & 4 & 3 & 0 & 3 & 4121.528 & -0.002 \\
\hline 8 & 0 & 8 & 7 & 1 & 7 & 7772.529 & 0.001 & & & & & & & & \\
\hline 8 & 1 & 8 & 7 & 1 & 7 & 7772.801 & 0.005 & & & & & & & & \\
\hline 8 & 0 & 8 & 7 & 0 & 7 & 7773.430 & 0.002 & & & & & & & & \\
\hline 8 & 1 & 8 & 7 & 0 & 7 & 7773.699 & 0.003 & & & & & & & & \\
\hline 2 & 1 & 2 & 1 & 0 & 1 & 2267.649 & 0.008 & & & & & & & & \\
\hline 5 & 4 & 1 & 4 & 4 & 0 & 5541.052 & 0.002 & & & & & & & & \\
\hline
\end{tabular}


Table S13. Observed rotational transitions and residuals (all the values in $\mathrm{MHz}$ ) for the ${ }^{13} \mathrm{C}_{9}$ and ${ }^{13} \mathrm{C}_{2}$ species of the cluster $12 \mathrm{C} 4-\mathrm{W} \mathrm{Cl}-\mathbf{W I}$ in the ground vibrational state for transitions of the type $J^{\prime}, K_{a}^{\prime}, K_{c}^{\prime} \leftarrow J$ ", $K^{\prime \prime}, K_{c}^{\prime \prime}$.

\begin{tabular}{rrrrrrrrrrrrrrrrrr}
\multicolumn{11}{c}{} \\
\hline$J$ & $K_{a}^{\prime}$ & $K_{a}^{\prime}$ & $J^{\prime \prime}$ & $K_{a}^{\prime \prime}$ & $K_{b}^{\prime \prime}$ & obs. & obs-calc & $J^{\prime}$ & $K_{a}^{\prime}$ & $K_{b}^{\prime}$ & $J^{\prime \prime}$ & $K_{a}^{\prime \prime}$ & $K_{b}^{\prime \prime}$ & obs. & obs-calc \\
\hline 8 & 1 & 8 & 7 & 0 & 7 & 7922.918 & -0.006 & 8 & 1 & 8 & 7 & 0 & 7 & 7913.369 & 0.004 \\
5 & 4 & 1 & 4 & 3 & 2 & 7731.781 & -0.003 & 8 & 0 & 8 & 7 & 1 & 7 & 7912.842 & 0.002 \\
5 & 3 & 2 & 4 & 2 & 3 & 7619.638 & -0.005 & 7 & 1 & 7 & 6 & 0 & 6 & 6955.201 & 0.000 \\
5 & 4 & 2 & 4 & 3 & 1 & 7613.108 & -0.002 & 7 & 0 & 7 & 6 & 1 & 6 & 6953.266 & -0.008 \\
7 & 1 & 6 & 6 & 2 & 5 & 7414.623 & 0.012 & 6 & 1 & 6 & 5 & 0 & 5 & 5998.851 & -0.001 \\
7 & 0 & 7 & 6 & 1 & 6 & 6961.611 & 0.012 & 5 & 1 & 5 & 4 & 0 & 4 & 5048.097 & -0.002 \\
6 & 2 & 5 & 5 & 1 & 4 & 6583.033 & -0.009 & 5 & 0 & 5 & 4 & 1 & 4 & 5025.609 & 0.006 \\
4 & 4 & 0 & 3 & 3 & 1 & 6551.826 & 0.003 & 4 & 1 & 4 & 3 & 0 & 3 & 4111.744 & -0.007 \\
4 & 4 & 1 & 3 & 3 & 0 & 6534.168 & 0.018 & 4 & 0 & 4 & 3 & 1 & 3 & 4044.288 & -0.011 \\
4 & 3 & 1 & 3 & 2 & 2 & 6149.523 & -0.006 & 7 & 2 & 5 & 6 & 3 & 4 & 7575.716 & 0.003 \\
6 & 0 & 6 & 5 & 1 & 5 & 5999.129 & -0.003 & 7 & 2 & 6 & 6 & 1 & 5 & 7475.230 & 0.010 \\
4 & 3 & 2 & 3 & 2 & 1 & 5806.710 & -0.010 & 5 & 3 & 3 & 4 & 2 & 2 & 6692.887 & 0.009 \\
5 & 2 & 4 & 4 & 1 & 3 & 5725.666 & -0.009 & 4 & 3 & 1 & 3 & 2 & 2 & 6142.490 & -0.007 \\
5 & 1 & 5 & 4 & 0 & 4 & 5054.348 & -0.004 & 5 & 2 & 4 & 4 & 1 & 3 & 5716.821 & -0.008 \\
5 & 0 & 5 & 4 & 1 & 4 & 5031.329 & 0.006 & & & & & & & & \\
3 & 2 & 1 & 2 & 1 & 2 & 4715.349 & 0.005 & & & & & & & &
\end{tabular}

Table S14. Observed rotational transitions and residuals (all the values in $\mathrm{MHz}$ ) for the ${ }^{13} \mathrm{C}_{8}$ and ${ }^{13} \mathrm{C}_{3}$ species of the cluster $12 \mathrm{C} 4-\mathrm{W} \mathrm{Cl}-\mathrm{Wl}$ in the ground vibrational state for transitions of the type $J^{\prime}, K_{a}^{\prime}, K_{c}^{\prime} \leftarrow J^{\prime \prime}, K^{\prime \prime}, K_{c}^{\prime \prime}$.

\begin{tabular}{rrrrrrrrrrrrrrrrrr}
\multicolumn{11}{c}{${ }^{13} \mathrm{C}_{8} 12 \mathrm{C} 4-\mathrm{H}_{2} \mathrm{O} A$} \\
\hline$J^{\prime}$ & $K_{a}^{\prime}$ & $K_{a}^{\prime}$ & $J^{\prime \prime}$ & $K_{a}^{\prime \prime}$ & $K_{b}^{\prime \prime}$ & obs. & obs-calc & $J^{\prime}$ & $K_{a}^{\prime}$ & $K_{b}^{\prime}$ & $J^{\prime \prime}$ & $K_{a}^{\prime \prime}$ & $K_{b}^{\prime \prime}$ & obs. & obs-calc \\
\hline 8 & 0 & 8 & 7 & 1 & 7 & 7909.260 & 0.009 & 8 & 1 & 8 & 7 & 0 & 7 & 7920.962 & -0.009 \\
8 & 1 & 8 & 7 & 0 & 7 & 7909.807 & 0.019 & 8 & 0 & 8 & 7 & 1 & 7 & 7920.408 & 0.006 \\
5 & 2 & 4 & 4 & 1 & 4 & 7165.471 & -0.009 & 7 & 1 & 7 & 6 & 0 & 6 & 6961.834 & 0.003 \\
7 & 1 & 7 & 6 & 0 & 6 & 6952.004 & -0.016 & 7 & 0 & 7 & 6 & 1 & 6 & 6959.757 & -0.006 \\
7 & 0 & 7 & 6 & 1 & 6 & 6950.049 & -0.006 & 6 & 1 & 6 & 5 & 0 & 5 & 6004.594 & -0.001 \\
6 & 0 & 6 & 5 & 1 & 5 & 5989.189 & 0.000 & 6 & 0 & 6 & 5 & 1 & 5 & 5997.398 & 0.005 \\
5 & 1 & 5 & 4 & 0 & 4 & 5045.817 & 0.008 & 7 & 2 & 6 & 6 & 1 & 5 & 7482.596 & 0.016 \\
5 & 0 & 5 & 4 & 1 & 4 & 5023.037 & 0.008 & 3 & 3 & 0 & 2 & 2 & 1 & 4870.679 & -0.003 \\
5 & 4 & 1 & 4 & 3 & 2 & 7715.453 & 0.018 & 4 & 1 & 4 & 3 & 0 & 3 & 4116.374 & -0.012 \\
6 & 3 & 4 & 5 & 2 & 3 & 7500.575 & -0.013 & 4 & 0 & 4 & 3 & 1 & 3 & 4046.568 & -0.008 \\
7 & 1 & 6 & 6 & 2 & 5 & 7402.339 & -0.009 & 4 & 3 & 1 & 3 & 2 & 2 & 6144.878 & 0.064 \\
6 & 2 & 5 & 5 & 1 & 4 & 6570.999 & -0.008 & & & & & & & &
\end{tabular}


Table S15. Observed rotational transitions and residuals (all the values in $\mathrm{MHz}$ ) for the ${ }^{13} \mathrm{C}_{5}$ and ${ }^{13} \mathrm{C}_{6}$ species of the cluster $12 \mathrm{C} 4-\mathrm{W}$ Cl-WI in the ground vibrational state for transitions of the type $J^{\prime}, K_{a}^{\prime}, K_{c}^{\prime} \leftarrow J$ ", $K^{\prime \prime}, K_{c}^{\prime \prime}$.

$$
{ }^{13} \mathrm{C}_{5} 12 \mathrm{C} 4-\mathrm{H}_{2} \mathrm{O} \text { A } \quad{ }^{13} \mathrm{C}_{6} 12 \mathrm{C} 4-\mathrm{H}_{2} \mathrm{O} \text { A }
$$

\begin{tabular}{rrrrrrrrrrrrrrrrr}
\hline$J^{\prime}$ & $K_{a}^{\prime}$ & $K_{a}^{\prime}$ & $J^{\prime \prime}$ & $K_{a}^{\prime \prime}$ & $K_{b}^{\prime \prime}$ & obs. & obs-calc & $J^{\prime}$ & $K_{a}^{\prime}$ & $K_{b}^{\prime}$ & $J^{\prime \prime}$ & $K_{a}^{\prime \prime}$ & $K_{b}^{\prime \prime}$ & obs. & obs-calc \\
\hline 8 & 0 & 8 & 7 & 1 & 7 & 7894.012 & 0.008 & 8 & 0 & 8 & 7 & 1 & 7 & 7905.305 & 0.006 \\
7 & 1 & 6 & 6 & 2 & 5 & 7380.126 & -0.002 & 7 & 0 & 7 & 6 & 1 & 6 & 6946.337 & -0.008 \\
7 & 1 & 7 & 6 & 0 & 6 & 6939.080 & 0.000 & 6 & 1 & 6 & 5 & 0 & 5 & 5994.049 & 0.001 \\
7 & 0 & 7 & 6 & 1 & 6 & 6936.456 & 0.003 & 6 & 0 & 6 & 5 & 1 & 5 & 5985.361 & -0.002 \\
6 & 1 & 5 & 5 & 2 & 4 & 6359.583 & -0.010 & 5 & 0 & 5 & 4 & 1 & 4 & 5018.264 & 0.006 \\
6 & 1 & 6 & 5 & 0 & 5 & 5985.646 & -0.001 & 5 & 4 & 2 & 4 & 3 & 1 & 7645.172 & 0.015 \\
6 & 0 & 6 & 5 & 1 & 5 & 5976.849 & -0.004 & 6 & 3 & 4 & 5 & 2 & 3 & 7545.594 & 0.001 \\
4 & 3 & 2 & 3 & 2 & 1 & 5828.431 & 0.001 & 7 & 2 & 5 & 6 & 3 & 4 & 7501.753 & 0.001 \\
5 & 1 & 4 & 4 & 2 & 3 & 5267.118 & 0.010 & 4 & 4 & 1 & 3 & 3 & 0 & 6567.303 & -0.017 \\
5 & 1 & 5 & 4 & 0 & 4 & 5038.748 & 0.007 & 7 & 1 & 6 & 6 & 2 & 5 & 7390.406 & -0.007 \\
5 & 0 & 5 & 4 & 1 & 4 & 5011.064 & -0.016 & 4 & 3 & 1 & 3 & 2 & 2 & 6149.751 & 0.002
\end{tabular}

Table S16. Observed rotational transitions and residuals (all the values in $\mathrm{MHz}$ ) for the ${ }^{13} \mathrm{C}_{12}$ species of the cluster $12 \mathrm{C} 4-\mathrm{W} \mathrm{Cl}-\mathbf{W I}$ in the ground vibrational state for transitions of the type $J^{\prime}, K_{a}^{\prime}, K_{c}^{\prime} \leftarrow J ", K_{a}^{\prime \prime}, K_{c}^{\prime \prime}$.

$$
{ }^{13} \mathrm{C}_{12} 12 \mathrm{C} 4-\mathrm{H}_{2} \mathrm{O} \text { A }
$$

\begin{tabular}{cccccccr}
\hline$J^{\prime}$ & $K_{a}^{\prime}$ & $K_{a}^{\prime}$ & $J^{\prime \prime}$ & $K_{a}^{\prime \prime}$ & $K_{b}^{\prime \prime}$ & obs. & obs-calc \\
\hline 8 & 1 & 8 & 7 & 0 & 7 & 7935.472 & 0.010 \\
7 & 1 & 7 & 6 & 0 & 6 & 6974.404 & 0.001 \\
7 & 0 & 7 & 6 & 1 & 6 & 6972.025 & -0.006 \\
4 & 4 & 1 & 3 & 3 & 0 & 6549.318 & -0.002 \\
4 & 4 & 0 & 3 & 3 & 1 & 6565.326 & 0.005 \\
6 & 1 & 5 & 5 & 2 & 4 & 6393.384 & -0.002 \\
4 & 3 & 1 & 3 & 2 & 2 & 6144.880 & -0.002 \\
6 & 1 & 6 & 5 & 0 & 5 & 6015.429 & -0.003 \\
6 & 0 & 6 & 5 & 1 & 5 & 6007.372 & 0.009 \\
4 & 3 & 2 & 3 & 2 & 1 & 5821.687 & -0.002 \\
5 & 1 & 4 & 4 & 2 & 3 & 5301.002 & 0.005 \\
5 & 1 & 5 & 4 & 0 & 4 & 5062.638 & -0.008 \\
4 & 0 & 4 & 3 & 1 & 3 & 4050.471 & -0.013
\end{tabular}


Table S17. Observed rotational transitions and residuals (all the values in $\mathrm{MHz}$ ) for the parent species of the cluster 12C4-W CIV-WI in the ground vibrational state for transitions of the type $J^{\prime}, K_{a}^{\prime}, K_{c}^{\prime} \leftarrow J$ ', $K^{\prime \prime}{ }_{a}, K_{c}^{\prime \prime}$.

\begin{tabular}{|c|c|c|c|c|c|c|c|c|c|c|c|c|c|c|c|}
\hline$J^{\prime}$ & $K_{a}^{\prime}$ & $K_{a}^{\prime}$ & J" & $K_{a}^{\prime \prime}$ & $K_{b}^{\prime \prime}$ & obs. & obs-calc & $J^{\prime}$ & $K_{a}^{\prime}$ & $K_{b}^{\prime}$ & J" & $K_{a}^{\prime \prime}$ & $K_{b}^{\prime \prime}$ & obs. & obs-calc \\
\hline 7 & 6 & 2 & 7 & 5 & 3 & 2566.359 & -0.015 & 4 & 3 & 1 & 3 & 2 & 1 & 6143.284 & 0.000 \\
\hline 2 & 1 & 1 & 1 & 0 & 1 & 2942.097 & -0.002 & 5 & 2 & 4 & 4 & 1 & 3 & 6158.134 & 0.002 \\
\hline 2 & 2 & 1 & 1 & 1 & 0 & 3131.713 & 0.009 & 5 & 3 & 3 & 4 & 3 & 2 & 6231.449 & -0.014 \\
\hline 2 & 2 & 0 & 1 & 1 & 0 & 3200.711 & 0.002 & 4 & 3 & 2 & 3 & 2 & 2 & 6301.514 & 0.004 \\
\hline 2 & 2 & 1 & 1 & 1 & 1 & 3289.183 & 0.003 & 4 & 3 & 1 & 3 & 2 & 2 & 6430.285 & 0.007 \\
\hline 3 & 0 & 3 & 2 & 1 & 2 & 3377.347 & -0.003 & 5 & 2 & 3 & 4 & 2 & 2 & 6499.996 & 0.000 \\
\hline 3 & 1 & 3 & 2 & 1 & 2 & 3407.401 & -0.002 & 5 & 3 & 2 & 4 & 3 & 1 & 6500.969 & -0.007 \\
\hline 3 & 0 & 3 & 2 & 0 & 2 & 3462.419 & -0.001 & 6 & 0 & 6 & 5 & 1 & 5 & 6643.310 & 0.004 \\
\hline 3 & 1 & 3 & 2 & 0 & 2 & 3492.478 & 0.004 & 6 & 1 & 6 & 5 & 1 & 5 & 6643.862 & 0.004 \\
\hline 3 & 1 & 2 & 2 & 1 & 1 & 3858.632 & -0.004 & 6 & 0 & 6 & 5 & 0 & 5 & 6645.571 & -0.001 \\
\hline 3 & 2 & 1 & 2 & 2 & 0 & 3898.400 & 0.001 & 6 & 1 & 6 & 5 & 0 & 5 & 6646.119 & -0.004 \\
\hline 4 & 1 & 3 & 3 & 2 & 1 & 4389.056 & -0.010 & 4 & 4 & 1 & 3 & 3 & 0 & 6671.461 & 0.001 \\
\hline 3 & 1 & 2 & 2 & 0 & 2 & 4416.135 & 0.002 & 4 & 4 & 0 & 3 & 3 & 0 & 6676.797 & 0.001 \\
\hline 4 & 0 & 4 & 3 & 1 & 3 & 4487.422 & -0.002 & 4 & 4 & 1 & 3 & 3 & 1 & 6692.650 & 0.000 \\
\hline 3 & 2 & 1 & 2 & 1 & 1 & 4488.022 & -0.002 & 4 & 4 & 0 & 3 & 3 & 1 & 6697.985 & -0.001 \\
\hline 4 & 1 & 4 & 3 & 1 & 3 & 4496.138 & 0.000 & 6 & 2 & 4 & 5 & 3 & 2 & 6751.802 & 0.003 \\
\hline 4 & 0 & 4 & 3 & 0 & 3 & 4517.479 & 0.001 & 5 & 3 & 3 & 4 & 2 & 2 & 7010.677 & 0.003 \\
\hline 4 & 1 & 4 & 3 & 0 & 3 & 4526.192 & 0.000 & 6 & 1 & 5 & 5 & 2 & 4 & 7061.792 & 0.000 \\
\hline 4 & 1 & 3 & 3 & 2 & 2 & 4676.061 & 0.000 & 6 & 2 & 5 & 5 & 2 & 4 & 7084.434 & 0.008 \\
\hline 4 & 2 & 3 & 3 & 2 & 2 & 4850.911 & -0.002 & 6 & 2 & 5 & 5 & 1 & 4 & 7153.440 & 0.000 \\
\hline 3 & 3 & 1 & 2 & 2 & 0 & 4909.592 & 0.004 & 5 & 2 & 3 & 4 & 1 & 3 & 7346.229 & -0.006 \\
\hline 3 & 3 & 0 & 2 & 2 & 0 & 4930.780 & 0.003 & 5 & 3 & 2 & 4 & 2 & 2 & 7408.959 & 0.004 \\
\hline 3 & 3 & 1 & 2 & 2 & 1 & 4978.595 & 0.003 & 5 & 1 & 4 & 4 & 0 & 4 & 7543.813 & 0.005 \\
\hline 3 & 3 & 0 & 2 & 2 & 1 & 4999.795 & 0.012 & 5 & 2 & 4 & 4 & 1 & 4 & 7604.108 & 0.001 \\
\hline 4 & 1 & 3 & 3 & 1 & 2 & 5018.454 & 0.000 & 6 & 2 & 4 & 5 & 2 & 3 & 7660.752 & -0.005 \\
\hline 4 & 2 & 3 & 3 & 1 & 2 & 5193.307 & 0.002 & 5 & 3 & 3 & 4 & 2 & 3 & 7682.065 & 0.004 \\
\hline 4 & 2 & 2 & 3 & 2 & 1 & 5235.297 & -0.008 & 7 & 0 & 7 & 6 & 1 & 6 & 7713.533 & -0.005 \\
\hline 5 & 0 & 5 & 4 & 1 & 4 & 5570.218 & 0.006 & 7 & 1 & 7 & 6 & 1 & 6 & 7713.671 & 0.005 \\
\hline 5 & 1 & 5 & 4 & 1 & 4 & 5572.480 & 0.002 & 7 & 0 & 7 & 6 & 0 & 6 & 7714.080 & -0.008 \\
\hline 5 & 0 & 5 & 4 & 0 & 4 & 5578.927 & 0.001 & 7 & 1 & 7 & 6 & 0 & 6 & 7714.220 & 0.003 \\
\hline 5 & 1 & 5 & 4 & 0 & 4 & 5581.190 & -0.002 & 5 & 4 & 2 & 4 & 3 & 1 & 7845.265 & -0.005 \\
\hline 4 & 2 & 2 & 3 & 1 & 2 & 5864.691 & -0.001 & 5 & 4 & 1 & 4 & 3 & 1 & 7888.960 & -0.001 \\
\hline 5 & 1 & 4 & 4 & 2 & 3 & 5914.261 & -0.006 & 6 & 3 & 4 & 5 & 2 & 3 & 7931.339 & 0.005 \\
\hline 4 & 1 & 3 & 3 & 0 & 3 & 5972.171 & 0.004 & 5 & 4 & 2 & 4 & 3 & 2 & 7974.033 & -0.006 \\
\hline 5 & 2 & 4 & 4 & 2 & 3 & 5983.272 & -0.008 & 6 & 4 & 2 & 5 & 4 & 1 & 7692.655 & -0.002 \\
\hline 4 & 3 & 2 & 3 & 2 & 1 & 6014.512 & -0.004 & 6 & 3 & 3 & 5 & 3 & 2 & 7867.373 & -0.006 \\
\hline 5 & 1 & 4 & 4 & 1 & 3 & 6089.124 & 0.005 & 7 & 3 & 4 & 6 & 4 & 2 & 7933.837 & 0.007 \\
\hline 4 & 2 & 3 & 3 & 1 & 3 & 6116.968 & 0.002 & & & & & & & & \\
\hline
\end{tabular}


Table S18. Observed rotational transitions and residuals (all the values in $\mathrm{MHz}$ ) for the ${ }^{18} \mathrm{O}$ species of the cluster $12 \mathrm{C} 4-\mathrm{W}$ CIV-WI in the ground vibrational state for transitions of the type $J^{\prime}, K_{a}^{\prime}, K_{c}^{\prime} \leftarrow J ", K_{a}^{\prime \prime}, K_{c}^{\prime \prime}$.

\begin{tabular}{|c|c|c|c|c|c|c|c|c|c|c|c|c|c|c|c|}
\hline & $K_{a}^{\prime}$ & $K_{a}^{\prime}$ & $J "$ & $K_{a}^{\prime \prime}$ & $K_{b}^{\prime \prime}$ & bs. & s-calc & $J^{\prime}$ & $K_{c}^{\prime}$ & $K_{b}^{\prime}$ & $J^{\prime \prime}$ & $k$ & $K_{b}^{\prime \prime}$ & s. & $s-c$ \\
\hline 2 & 1 & 2 & 1 & 1 & 1 & 2282.966 & 0.004 & 5 & 2 & 4 & 4 & 2 & 3 & 5934.667 & -0.004 \\
\hline 8 & 2 & 6 & 8 & 1 & 7 & 2632.851 & -0.005 & 4 & 2 & 3 & 3 & 1 & 3 & .088 & -0.003 \\
\hline 2 & 1 & 1 & 1 & 0 & 1 & 2885.323 & -0.006 & 4 & 3 & 1 & 3 & 2 & 1 & 6025.021 & -0.002 \\
\hline 2 & 2 & 0 & 1 & 1 & 0 & 3134.582 & -0.001 & 5 & 1 & 4 & 4 & 1 & 3 & 6037.846 & 0.007 \\
\hline 2 & 2 & 1 & 1 & 1 & 1 & 3217.667 & -0.001 & 5 & 3 & 3 & 4 & 3 & 2 & 6160.758 & 0.003 \\
\hline 3 & 1 & 2 & 2 & 2 & 1 & 3310.191 & -0.009 & 4 & 3 & 2 & 3 & 2 & 2 & 6171.757 & 0.001 \\
\hline 3 & 0 & 3 & 2 & 1 & 2 & 3361.031 & 0.000 & 4 & 3 & 1 & 3 & 2 & 2 & 6285.766 & 0.005 \\
\hline 3 & 1 & 3 & 2 & 1 & 2 & 3391.127 & -0.011 & 5 & 2 & 3 & 4 & 2 & 2 & 6411.774 & 0.000 \\
\hline 3 & 0 & 3 & 2 & 0 & 2 & 3444.115 & -0.001 & 4 & 4 & 1 & 3 & 3 & 0 & 6527.595 & -0.001 \\
\hline 3 & 1 & 3 & 2 & 0 & 2 & 3474.224 & 0.002 & 4 & 4 & 0 & 3 & 3 & 0 & 6532.157 & -0.003 \\
\hline 3 & 2 & 2 & 2 & 2 & 1 & 3642.544 & 0.006 & 4 & 4 & 1 & 3 & 3 & 1 & 6546.215 & -0.006 \\
\hline 3 & 1 & 2 & 2 & 1 & 1 & 3808.707 & -0.002 & 4 & 4 & 0 & 3 & 3 & 1 & 6550.785 & 0.000 \\
\hline 3 & 2 & 1 & 2 & 2 & 0 & 3840.946 & -0.016 & 6 & 0 & 6 & 5 & 1 & 5 & 6624.463 & 0.001 \\
\hline 3 & 2 & 2 & 2 & 1 & 1 & 4141.063 & 0.016 & 6 & 1 & 6 & 5 & 1 & 5 & 6625.051 & -0.007 \\
\hline 3 & 2 & 1 & 2 & 1 & 1 & 4401.784 & -0.0 & 6 & 0 & 6 & 5 & 0 & 5 & .849 & -0.002 \\
\hline 4 & 0 & 4 & 3 & 1 & 3 & 4469.563 & -0.00 & 6 & 1 & 6 & 5 & 0 & 5 & 6627.452 & 0.004 \\
\hline 4 & 1 & 4 & 3 & 1 & 3 & 4478.509 & -0.0 & 6 & 2 & 4 & 5 & 3 & 2 & 658 & 0.010 \\
\hline 4 & 1 & 4 & 3 & 0 & 3 & 4508.628 & -0.001 & 6 & 2 & 5 & 5 & 2 & 4 & 373 & -0.006 \\
\hline 3 & 2 & 2 & 2 & 1 & 2 & 4577.255 & 0.009 & 6 & 2 & 4 & 5 & 3 & 3 & 980 & -0.007 \\
\hline 4 & 1 & 3 & 3 & 2 & 2 & 4632.394 & 0.00 & 6 & 2 & 5 & 5 & 1 & 4 & 788 & -0.012 \\
\hline 3 & 3 & 1 & 2 & 2 & 0 & 4807.875 & 0.00 & 7 & 4 & 3 & 6 & 5 & 2 & 69 & 0.004 \\
\hline 3 & 3 & 0 & 2 & 2 & 0 & 4826.499 & 0.00 & 5 & 2 & 3 & 4 & 1 & 3 & 82 & 0.004 \\
\hline 3 & 3 & 1 & 2 & 2 & 1 & 4870.184 & -0.004 & 5 & 3 & 2 & 4 & 2 & 2 & 7269.661 & 0.006 \\
\hline 3 & 3 & 0 & 2 & 2 & 1 & 4888.809 & -0.0 & 5 & 1 & 4 & 4 & 0 & 4 & 7386.782 & 0.007 \\
\hline 4 & 1 & 3 & 3 & 1 & 2 & 4964.721 & -0.0 & 5 & 2 & 4 & 4 & 1 & 4 & 251 & 0.011 \\
\hline 4 & 2 & 3 & 3 & 1 & 2 & 5138.315 & -0.007 & 7 & 0 & 7 & 6 & 1 & 6 & 7694.196 & -0.006 \\
\hline 4 & 2 & 2 & 3 & 2 & 1 & 5158.460 & 0.000 & 7 & 1 & 7 & 6 & 1 & 6 & 7694.348 & 0.004 \\
\hline 5 & 0 & 5 & 4 & 1 & 4 & 5551.812 & 0.001 & 7 & 0 & 7 & 6 & 0 & 6 & 7694.805 & 0.007 \\
\hline 5 & 1 & 5 & 4 & 1 & 4 & 5554.203 & 0.003 & 5 & 4 & 1 & 4 & 3 & 1 & 7732.767 & -0.005 \\
\hline 5 & 0 & 5 & 4 & 0 & 4 & 5560.776 & 0.009 & 6 & 3 & 3 & 5 & 3 & 2 & 7749.548 & -0.005 \\
\hline 5 & 1 & 5 & 4 & 0 & 4 & 5563.168 & 0.011 & 5 & 4 & 2 & 4 & 3 & 2 & 7809.201 & -0.002 \\
\hline 4 & 2 & 2 & 3 & 1 & 2 & 5751.534 & -0.002 & 6 & 3 & 4 & 5 & 2 & 3 & 7844.067 & 0.003 \\
\hline 4 & 1 & 3 & 3 & 0 & 3 & 5848.620 & 0.013 & 7 & 3 & 4 & 6 & 4 & 2 & 7857.863 & -0.006 \\
\hline 5 & 1 & 4 & 4 & 2 & 3 & 5864.255 & 0.006 & & & & & & & & \\
\hline
\end{tabular}


Table S19. Observed rotational transitions and residuals (all the values in $\mathrm{MHz}$ ) for the parent species of the cluster $12 \mathrm{C} 4-\mathrm{W}$ CIV-WII in the ground vibrational state for transitions of the type $J^{\prime}, K_{a}^{\prime}, K_{c}^{\prime} \leftarrow J^{\prime \prime}, K^{\prime \prime}, K_{c}^{\prime \prime}$.

\begin{tabular}{cccccccc}
$J$ & $K_{a}^{\prime}$ & $K_{a}^{\prime}$ & $J^{\prime \prime}$ & $K_{a}^{\prime \prime}$ & $K_{b}^{\prime \prime}$ & obs. & obs-calc \\
\hline 2 & 1 & 1 & 1 & 0 & 1 & 3036.788 & 0.004 \\
2 & 2 & 0 & 1 & 1 & 0 & 3215.988 & 0.000 \\
2 & 2 & 1 & 1 & 1 & 1 & 3302.006 & 0.007 \\
3 & 2 & 1 & 2 & 1 & 1 & 4591.614 & 0.004 \\
3 & 1 & 2 & 2 & 0 & 2 & 4596.209 & 0.002 \\
3 & 2 & 2 & 2 & 1 & 2 & 4754.084 & -0.003 \\
3 & 3 & 0 & 2 & 2 & 0 & 4911.958 & -0.003 \\
3 & 3 & 1 & 2 & 2 & 1 & 4978.424 & 0.008 \\
4 & 1 & 3 & 3 & 0 & 3 & 6209.722 & 0.004 \\
4 & 2 & 3 & 3 & 1 & 3 & 6269.633 & 0.003 \\
4 & 3 & 2 & 3 & 2 & 2 & 6376.146 & 0.000 \\
4 & 4 & 0 & 3 & 3 & 0 & 6639.747 & -0.004 \\
4 & 4 & 1 & 3 & 3 & 1 & 6673.152 & 0.007 \\
6 & 2 & 4 & 5 & 3 & 2 & 6681.237 & 0.001 \\
6 & 3 & 3 & 5 & 4 & 1 & 7072.477 & -0.001 \\
5 & 3 & 2 & 4 & 2 & 2 & 7598.142 & 0.007 \\
5 & 2 & 3 & 4 & 1 & 3 & 7674.940 & 0.004 \\
5 & 1 & 4 & 4 & 0 & 4 & 7804.934 & -0.009 \\
5 & 2 & 4 & 4 & 1 & 4 & 7821.043 & -0.006 \\
5 & 3 & 3 & 4 & 2 & 3 & 7844.310 & -0.006 \\
5 & 4 & 1 & 4 & 3 & 1 & 7886.919 & -0.008
\end{tabular}


Table S20. Observed rotational transitions and residuals (all the values in $\mathrm{MHz}$ ) for the parent $_{2}$ species of the cluster $12 \mathrm{C} 4-\mathbf{W}_{2} \mathbf{C I V}-\mathbf{W}_{\mathbf{2}}$ in the ground vibrational state for transitions of the type $J^{\prime}, K_{a}^{\prime}, K_{c}^{\prime} \leftarrow J$ ', $K^{\prime \prime}, K_{c}^{\prime \prime}$.

\begin{tabular}{|c|c|c|c|c|c|c|c|c|c|c|c|c|c|c|c|}
\hline J' & $K_{a}^{\prime}$ & $K_{a}^{\prime}$ & J" & $K_{a}^{\prime \prime}$ & $K_{b}^{\prime \prime}$ & obs. & obs-calc & $J^{\prime}$ & $K_{a}^{\prime}$ & $K_{b}^{\prime}$ & J" & $K_{a}^{\prime \prime}$ & $K_{b}^{\prime \prime}$ & obs. & obs-calc \\
\hline 2 & 2 & 0 & 1 & 1 & 0 & 2367.210 & -0.005 & 5 & 5 & 1 & 4 & 4 & 0 & 6100.726 & 0.009 \\
\hline 3 & 0 & 3 & 2 & 1 & 2 & 2992.755 & -0.002 & 5 & 5 & 0 & 4 & 4 & 0 & 6100.726 & 0.009 \\
\hline 3 & 2 & 1 & 2 & 1 & 1 & 3388.240 & -0.004 & 5 & 5 & 1 & 4 & 4 & 1 & 6100.806 & 0.005 \\
\hline 3 & 3 & 1 & 2 & 2 & 0 & 3614.649 & -0.004 & 5 & 5 & 0 & 4 & 4 & 1 & 6100.806 & 0.005 \\
\hline 3 & 3 & 0 & 2 & 2 & 0 & 3615.435 & -0.002 & 6 & 2 & 5 & 5 & 1 & 4 & 6276.092 & 0.006 \\
\hline 3 & 3 & 1 & 2 & 2 & 1 & 3620.647 & -0.004 & 7 & 3 & 5 & 6 & 4 & 3 & 6469.457 & 0.010 \\
\hline 3 & 3 & 0 & 2 & 2 & 1 & 3621.432 & -0.002 & 6 & 2 & 4 & 5 & 1 & 4 & 6544.049 & -0.003 \\
\hline 4 & 1 & 3 & 3 & 2 & 1 & 3891.470 & -0.003 & 6 & 3 & 4 & 5 & 2 & 3 & 6604.262 & -0.003 \\
\hline 4 & 0 & 4 & 3 & 1 & 3 & 4019.054 & -0.001 & 6 & 1 & 5 & 5 & 0 & 5 & 6621.734 & -0.003 \\
\hline 4 & 1 & 4 & 3 & 0 & 3 & 4086.455 & -0.001 & 6 & 3 & 3 & 5 & 2 & 3 & 6659.936 & -0.003 \\
\hline 4 & 2 & 3 & 3 & 1 & 2 & 4343.055 & -0.004 & 6 & 2 & 5 & 5 & 1 & 5 & 6696.856 & 0.001 \\
\hline 4 & 1 & 3 & 3 & 0 & 3 & 4375.184 & -0.001 & 6 & 3 & 4 & 5 & 2 & 4 & 6762.085 & 0.005 \\
\hline 4 & 2 & 2 & 3 & 1 & 2 & 4420.657 & -0.004 & 6 & 3 & 3 & 5 & 2 & 4 & 6817.763 & 0.009 \\
\hline 4 & 2 & 3 & 3 & 1 & 3 & 4518.727 & 0.002 & 7 & 2 & 5 & 6 & 3 & 3 & 6878.584 & 0.001 \\
\hline 4 & 3 & 1 & 3 & 2 & 1 & 4635.427 & 0.001 & 6 & 4 & 3 & 5 & 3 & 2 & 6904.276 & 0.000 \\
\hline 4 & 3 & 2 & 3 & 2 & 2 & 4658.576 & 0.001 & 6 & 4 & 2 & 5 & 3 & 2 & 6907.917 & 0.001 \\
\hline 4 & 3 & 1 & 3 & 2 & 2 & 4663.928 & 0.002 & 6 & 4 & 3 & 5 & 3 & 3 & 6924.611 & -0.002 \\
\hline 4 & 4 & 1 & 3 & 3 & 0 & 4859.002 & 0.000 & 6 & 4 & 2 & 5 & 3 & 3 & 6928.250 & -0.003 \\
\hline 4 & 4 & 0 & 3 & 3 & 0 & 4859.085 & -0.002 & 7 & 2 & 5 & 6 & 3 & 4 & 6934.257 & 0.000 \\
\hline 4 & 4 & 1 & 3 & 3 & 1 & 4859.786 & -0.001 & 7 & 0 & 7 & 6 & 1 & 6 & 7045.942 & 0.003 \\
\hline 5 & 1 & 4 & 4 & 2 & 2 & 4914.054 & -0.008 & 7 & 1 & 7 & 6 & 0 & 6 & 7053.634 & -0.003 \\
\hline 5 & 0 & 5 & 4 & 1 & 4 & 5034.939 & 0.003 & 7 & 1 & 6 & 6 & 2 & 5 & 7101.706 & 0.001 \\
\hline 5 & 1 & 5 & 4 & 0 & 4 & 5070.565 & 0.000 & 6 & 5 & 2 & 5 & 4 & 1 & 7129.903 & -0.004 \\
\hline 5 & 2 & 4 & 4 & 1 & 3 & 5313.455 & 0.002 & 6 & 5 & 1 & 5 & 4 & 1 & 7129.996 & -0.001 \\
\hline 5 & 2 & 3 & 4 & 1 & 3 & 5471.264 & -0.003 & 6 & 5 & 2 & 5 & 4 & 2 & 7130.656 & -0.001 \\
\hline 5 & 1 & 4 & 4 & 0 & 4 & 5491.339 & 0.004 & 6 & 5 & 1 & 5 & 4 & 2 & 7130.746 & 0.000 \\
\hline 6 & 3 & 3 & 5 & 4 & 2 & 5501.642 & 0.003 & 7 & 2 & 6 & 6 & 1 & 5 & 7238.725 & 0.004 \\
\hline 5 & 2 & 4 & 4 & 1 & 4 & 5602.182 & 0.000 & 6 & 6 & 1 & 5 & 5 & 0 & 7342.040 & -0.003 \\
\hline 5 & 3 & 3 & 4 & 2 & 2 & 5627.361 & 0.003 & 6 & 6 & 0 & 5 & 5 & 0 & 7342.040 & -0.003 \\
\hline 5 & 3 & 2 & 4 & 2 & 2 & 5647.694 & 0.000 & 6 & 6 & 1 & 5 & 5 & 1 & 7342.040 & -0.003 \\
\hline 5 & 3 & 3 & 4 & 2 & 3 & 5704.959 & -0.002 & 6 & 6 & 0 & 5 & 5 & 1 & 7342.040 & -0.003 \\
\hline 5 & 3 & 2 & 4 & 2 & 3 & 5725.296 & -0.001 & 8 & 3 & 6 & 7 & 4 & 4 & 7480.775 & -0.020 \\
\hline 5 & 2 & 3 & 4 & 1 & 4 & 5759.999 & 0.003 & 7 & 3 & 5 & 6 & 2 & 4 & 7563.303 & -0.001 \\
\hline 6 & 2 & 4 & 5 & 3 & 2 & 5810.418 & -0.001 & 7 & 2 & 5 & 6 & 1 & 5 & 7641.843 & -0.001 \\
\hline 6 & 2 & 4 & 5 & 3 & 3 & 5830.751 & -0.005 & 7 & 3 & 4 & 6 & 2 & 4 & 7684.084 & 0.006 \\
\hline 5 & 4 & 2 & 4 & 3 & 1 & 5885.619 & 0.004 & 7 & 1 & 6 & 6 & 0 & 6 & 7755.728 & 0.004 \\
\hline 5 & 4 & 1 & 4 & 3 & 1 & 5886.367 & 0.002 & 7 & 2 & 6 & 6 & 1 & 6 & 7800.511 & 0.002 \\
\hline 5 & 4 & 2 & 4 & 3 & 2 & 5890.965 & -0.001 & 7 & 3 & 5 & 6 & 2 & 5 & 7831.264 & -0.006 \\
\hline 5 & 4 & 1 & 4 & 3 & 2 & 5891.714 & -0.002 & 8 & 2 & 6 & 7 & 3 & 4 & 7913.231 & 0.008 \\
\hline 6 & 1 & 5 & 5 & 2 & 3 & 5896.683 & 0.006 & 7 & 4 & 3 & 6 & 3 & 3 & 7920.138 & 0.006 \\
\hline
\end{tabular}


Table S20 (continued)

\begin{tabular}{|c|c|c|c|c|c|c|c|c|c|c|c|c|c|c|c|}
\hline & , & $K^{\prime}$ & $"$ & " & " & & s-calc & J' & $K_{a}^{\prime}$ & $b_{b}$ & J" & $K_{a}^{\prime \prime}$ & $K_{b}^{\prime \prime}$ & bs. & 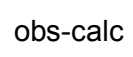 \\
\hline 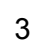 & 0 & 3 & 2 & 1 & 2 & .285 & & 5 & 3 & 0 & 4 & 4 & 0 & & \\
\hline 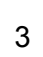 & 3 & 1 & 2 & 2 & 0 & 63 & & 5 & 5 & 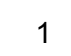 & . & 4 & 1 & & \\
\hline 3 & 3 & 0 & 2 & 2 & 0 & 563.989 & & 3 & 5 & 0 & 4 & 4 & 1 & 11.526 & -0.010 \\
\hline 3 & 3 & 1 & 2 & 2 & 1 & 568.255 & -0.001 & 6 & 1 & 6 & 5 & 0 & 5 & 6016.064 & -0.005 \\
\hline 3 & 3 & 0 & 2 & 2 & 1 & & & 6 & 2 & 4 & 5 & 1 & 4 & & 004 \\
\hline 4 & 1 & 4 & 3 & 0 & 3 & 4056 & -0. & 6 & 3 & 3 & 5 & 2 & 3 & & .004 \\
\hline 4 & 2 & 3 & 3 & 1 & 2 & & & 6 & 3 & 4 & 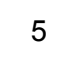 & 2 & 4 & & .000 \\
\hline 4 & 1 & 3 & 3 & 0 & 3 & 431 & $0 c$ & 6 & 3 & 3 & 5 & 2 & 4 & & 0.005 \\
\hline 4 & 2 & 2 & 3 & 1 & 2 & 4 & -0 & 7 & 2 & 5 & 6 & 3 & 3 & & 003 \\
\hline 4 & 3 & 2 & 3 & 2 & 1 & 4570.954 & $00 \varepsilon$ & 6 & 4 & 3 & 5 & 3 & 2 & 681 & .009 \\
\hline 4 & 3 & 2 & 3 & 2 & 2 & 459 & 00 & 6 & 4 & 2 & 5 & 3 & 2 & 68 & .008 \\
\hline 4 & 3 & 1 & 3 & 2 & 2 & 4598 & $00^{\prime}$ & 6 & 4 & 3 & 5 & 3 & 3 & 683 & -0.003 \\
\hline 4 & 4 & 0 & 3 & 3 & 0 & 4788.585 & -0.00 & 6 & 4 & 2 & 5 & 3 & 3 & 683 & 0.002 \\
\hline 4 & 4 & 1 & 3 & 3 & 1 & 478 & & 7 & 0 & 7 & 6 & 1 & 6 & & .002 \\
\hline 5 & 0 & 5 & 4 & 1 & 4 & 499 & 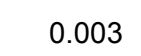 & 7 & 1 & 7 & 6 & 0 & 6 & 700 & 0.000 \\
\hline 5 & 1 & 5 & 4 & 0 & 4 & & & 6 & 5 & 1 & 5 & 4 & 1 & & \\
\hline 5 & 2 & 4 & 4 & 1 & 3 & 52 & 0 & 6 & 5 & 2 & 5 & 4 & 2 & & 10 \\
\hline 5 & 2 & 3 & 4 & 1 & 3 & 539 & & 6 & 6 & 1 & 5 & 5 & 0 & 723 & \\
\hline 5 & 2 & 4 & 4 & 1 & 4 & 552 & 0 & 6 & 6 & 0 & 5 & 5 & 0 & 723 & -0.002 \\
\hline 5 & 3 & 2 & 4 & 2 & 2 & $557 \varepsilon$ & & 6 & 6 & 1 & 5 & 5 & 1 & 723 & \\
\hline 5 & 3 & 3 & 4 & 2 & 3 & 562 & & 6 & 6 & 0 & 5 & 5 & 1 & & \\
\hline 5 & 2 & 3 & 4 & 1 & 4 & 565 & & 7 & 3 & 4 & 6 & 2 & 4 & 758 & .000 \\
\hline 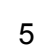 & 4 & 2 & 4 & 3 & 1 & 580 & $-0 . C$ & 7 & 1 & 6 & 6 & 0 & 6 & & .001 \\
\hline 5 & 4 & 1 & 4 & 3 & 1 & 5805.861 & 0.000 & 7 & 3 & 5 & 6 & 2 & 5 & 772 & 0.009 \\
\hline 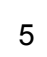 & 4 & 2 & 4 & 3 & 2 & 5809.318 & -0.006 & 7 & 4 & 4 & 6 & 3 & 3 & 7814 & 0.011 \\
\hline 5 & 4 & 1 & 4 & 3 & 2 & 5809.827 & -0.006 & 7 & 4 & 4 & 6 & 3 & 4 & 7857.100 & -0.008 \\
\hline 6 & 1 & 5 & 5 & 2 & 4 & 5989.636 & -0.002 & 7 & 4 & 3 & 6 & 3 & 4 & 7865.847 & -0.003 \\
\hline 6 & 0 & 6 & 5 & 1 & 5 & 5996.086 & & 8 & 1 & 8 & 7 & 0 & 7 & 7991 & 0.004 \\
\hline 5 & 5 & 1 & 4 & 4 & 0 & 6011.476 & -0.002 & 7 & 4 & 3 & 6 & 3 & 4 & 7975.809 & 0.003 \\
\hline 6 & 0 & 6 & 5 & 1 & 5 & & & 7 & 4 & 4 & 6 & 3 & 4 & 7963.073 & -0.014 \\
\hline 6 & 1 & 5 & 5 & 2 & 4 & 6054.495 & 0.003 & 7 & 4 & 3 & 6 & 3 & 4 & 7975.809 & 0.003 \\
\hline
\end{tabular}


Table S21. Observed rotational transitions and residuals (all the values in $\mathrm{MHz}$ ) for the ${ }^{18} \mathrm{O}_{\mathrm{w}}(1)$ species of the cluster $12 \mathrm{C} 4-\mathrm{W}_{2} \mathbf{C I V}-\mathbf{W}_{\mathbf{2}}$ in the ground vibrational state for transitions of the type $J^{\prime}, K_{a}^{\prime}, K_{c}^{\prime} \leftarrow J$ ', $K^{\prime \prime}, K_{c}^{\prime \prime}$.

\begin{tabular}{|c|c|c|c|c|c|c|c|c|c|c|c|c|c|c|c|}
\hline & $K_{a}^{\prime}$ & $K^{\prime}$ & "l" & $K_{a}^{\prime \prime}$ & & & & & $K_{a}^{\prime}$ & $K_{b}^{\prime}$ & $J^{\prime \prime}$ & $k$ & $K_{b}^{\prime \prime}$ & & \\
\hline 3 & 0 & 3 & 2 & 1 & 2 & 2966.285 & -0.007 & 5 & 5 & 0 & 4 & 4 & 0 & 6011.476 & -0.002 \\
\hline 3 & 3 & 1 & 2 & 2 & 0 & 7 & & 5 & 5 & 1 & 4 & 4 & 1 & & \\
\hline 3 & 3 & 0 & 2 & 2 & 0 & 563.989 & .002 & 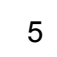 & 5 & 0 & 4 & 4 & 1 & 6011.526 & -0.010 \\
\hline 3 & 3 & 1 & 2 & 2 & 1 & & & 6 & 1 & 6 & 5 & 0 & 5 & & \\
\hline 3 & 3 & 0 & 2 & 2 & 1 & 3568.843 & 007 & 6 & 2 & 4 & 5 & 1 & 4 & & -0.004 \\
\hline 4 & 1 & 4 & 3 & 0 & 3 & 4056. & -0.1 & 6 & 3 & 3 & 5 & 2 & 3 & & -0.004 \\
\hline 4 & 2 & 3 & 3 & 1 & 2 & 4 & 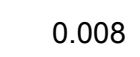 & 6 & 3 & 4 & 5 & 2 & 4 & & .000 \\
\hline 4 & 1 & 3 & 3 & 0 & 3 & 43 & 0.0 & 6 & 3 & 3 & 5 & 2 & 4 & & 005 \\
\hline 4 & 2 & 2 & 3 & 1 & 2 & 436 & -0.006 & 7 & 2 & 5 & 6 & 3 & 3 & & -0.003 \\
\hline 4 & 3 & 2 & 3 & 2 & 1 & 457 & 008 & 6 & 4 & 3 & 5 & 3 & 2 & 0 & .009 \\
\hline 4 & 3 & 2 & 3 & 2 & 2 & 459 & 0.00 & 6 & 4 & 2 & 5 & 3 & 2 & 68 & .008 \\
\hline 4 & 3 & 1 & 3 & 2 & 2 & 45 & 0.0 & 6 & 4 & 3 & 5 & 3 & 3 & & -0.003 \\
\hline 4 & 4 & 0 & 3 & 3 & 0 & 4788.585 & -0.00 & 6 & 4 & 2 & 5 & 3 & 3 & $683^{\circ}$ & 0.002 \\
\hline 4 & 4 & 1 & 3 & 3 & 1 & & -0.0 & 7 & 0 & 7 & 6 & 1 & 6 & & .002 \\
\hline 5 & 0 & 5 & 4 & 1 & 4 & 499 & סم م & 7 & 1 & 7 & 6 & 0 & 6 & 70 & 0.000 \\
\hline 5 & 1 & 5 & 4 & 0 & 4 & & & 6 & 5 & 1 & 5 & 4 & 1 & & \\
\hline 5 & 2 & 4 & 4 & 1 & 3 & & 0.01 & 6 & 5 & 2 & 5 & 4 & 2 & & 10 \\
\hline 5 & 2 & 3 & 4 & 1 & 3 & & & 6 & 0 & 1 & 5 & 5 & 0 & & \\
\hline 5 & 2 & 4 & 4 & 1 & 4 & & & 6 & 6 & 0 & 5 & 5 & 0 & & \\
\hline 5 & 3 & 2 & 4 & 2 & 2 & & $-0 .($ & 6 & 6 & 1 & 5 & 5 & 1 & & 02 \\
\hline 5 & 3 & 3 & 4 & 2 & 3 & & & 6 & 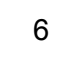 & 0 & 5 & - & 1 & & -0 \\
\hline 5 & 2 & 3 & 4 & 1 & 4 & & 0 & 7 & 3 & 4 & 6 & 2 & 4 & & 00 \\
\hline 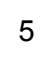 & 4 & 2 & 4 & 3 & 1 & 580 & -0.0 & 7 & 1 & 6 & 6 & 0 & 6 & & 01 \\
\hline 5 & 4 & 1 & 4 & 3 & 1 & & & 7 & 3 & 5 & 6 & 2 & 5 & & 09 \\
\hline 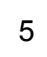 & 4 & 2 & 4 & 3 & 2 & 5809.3 & -0.006 & 7 & 4 & 4 & 6 & 3 & 3 & 308 & 0.011 \\
\hline 5 & 4 & 1 & 4 & 3 & 2 & 5809. & -0.006 & 7 & 4 & 4 & 6 & 3 & 4 & 7857 & -0.008 \\
\hline 6 & 1 & 5 & 5 & 2 & 4 & 5989.636 & -0.002 & 7 & 4 & 3 & 6 & 3 & 4 & 7865.847 & -0.003 \\
\hline 6 & 0 & 6 & 5 & 1 & 5 & 5996.086 & -0.010 & 8 & 1 & 8 & 7 & 0 & 7 & 7991.653 & 0.004 \\
\hline 5 & 5 & 1 & 4 & 4 & 0 & & -0.002 & 7 & 4 & 3 & 6 & 3 & 4 & 7975.809 & 0.003 \\
\hline 6 & 0 & 6 & 5 & 1 & 5 & 6042.837 & 0.002 & 7 & 4 & 4 & 6 & 3 & 4 & 7963.073 & -0.014 \\
\hline 6 & 1 & 5 & 5 & 2 & 4 & 6054.495 & 0.003 & 7 & 4 & 3 & 6 & 3 & 4 & 7975.809 & 0.003 \\
\hline
\end{tabular}


Table S22. Observed rotational transitions and residuals (all the values in $\mathrm{MHz}$ ) for the ${ }^{18} \mathrm{O}_{\mathrm{w}}(2)$ species of the cluster $12 \mathrm{C} 4-\mathrm{W}_{2} \mathbf{C I V}-\mathbf{W}_{\mathbf{2}}$ in the ground vibrational state for transitions of the type $J^{\prime}, K_{a}^{\prime}, K_{c}^{\prime} \leftarrow J$ ', $K^{\prime \prime}, K_{c}^{\prime \prime}$.

\begin{tabular}{|c|c|c|c|c|c|c|c|c|c|c|c|c|c|c|c|}
\hline 3 & 0 & 3 & 2 & 1 & 2 & 63.5 & 004 & 5 & 5 & 0 & 4 & 4 & 1 & 5963.219 & 0.008 \\
\hline 3 & 2 & 1 & 2 & 1 & 1 & 326.514 & 1.002 & ( & 0 & 6 & 5 & 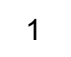 & 5 & 98 & .003 \\
\hline 3 & 3 & 1 & 2 & 2 & 0 & 37. & 000 & 6 & 1 & 6 & 5 & 0 & 5 & & 0.009 \\
\hline 3 & 3 & 0 & 2 & 2 & 0 & 5 & 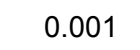 & 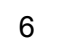 & 2 & 5 & 5 & 1 & 4 & & .021 \\
\hline 4 & 1 & 3 & 3 & 2 & 1 & 40.771 & -0.009 & 6 & 2 & 4 & 5 & 1 & 4 & 92.098 & 0.006 \\
\hline 4 & 0 & 4 & 3 & 1 & 3 & & 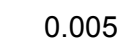 & 6 & 3 & 4 & 5 & 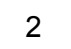 & 3 & & .003 \\
\hline 4 & 1 & 4 & 3 & 0 & 3 & 4072 & 0.00 & 6 & 3 & 3 & 5 & 2 & 3 & & 0.003 \\
\hline 4 & 2 & 2 & 3 & 1 & 2 & & 0 & & 3 & 4 & $\tau$ & 0 & 4 & & 000 \\
\hline 4 & 3 & 2 & 3 & 2 & 1 & 4547 & 00 & 6 & 3 & 3 & 5 & 2 & 4 & 01 & 0.016 \\
\hline 4 & 3 & 1 & 3 & 2 & 1 & 454 & -0.0 & 0 & 2 & 4 & 5 & 1 & 5 & & .007 \\
\hline 4 & 3 & 2 & 3 & 2 & 2 & 4560.293 & -0.002 & 6 & 4 & 2 & 5 & 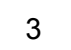 & 2 & 53 & 0.001 \\
\hline 4 & 3 & 1 & 3 & 2 & 2 & 4562. & 000 & 6 & 4 & 3 & 5 & 3 & 3 & & .003 \\
\hline 4 & 4 & 1 & 3 & 3 & 0 & 4750.873 & .005 & 6 & 4 & 2 & 5 & 3 & 3 & 53 & 0.006 \\
\hline 4 & 4 & 0 & 3 & 3 & 0 & 4750.873 & 0.005 & 6 & 5 & 1 & 5 & 4 & 1 & 12 & 0.004 \\
\hline 4 & 4 & 1 & 3 & 3 & 1 & 4751.097 & -0.010 & 6 & 5 & 2 & 5 & 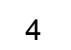 & 2 & & 0.006 \\
\hline 5 & 1 & 4 & 4 & 2 & 2 & 4866.857 & 0.000 & 7 & 1 & 6 & 6 & 2 & 5 & 699 & -0.002 \\
\hline 5 & 1 & 5 & 4 & 0 & 4 & 5055 & -0.006 & 7 & 0 & 7 & 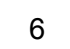 & 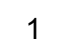 & 6 & & .004 \\
\hline 5 & 2 & 4 & 4 & 1 & 3 & 5277 & 0.000 & 7 & 1 & 7 & 6 & 0 & 6 & 40 & 0.008 \\
\hline 5 & 2 & 3 & 4 & 1 & 3 & 5358. & $-0.0 c$ & 6 & 6 & 1 & 5 & 5 & 0 & & -0.004 \\
\hline 5 & 3 & 3 & 4 & 2 & 2 & 5 & -0.0 & 6 & 6 & 0 & 5 & 5 & 0 & & -0.004 \\
\hline 5 & 3 & 2 & 4 & 2 & 2 & 5554 & 0.002 & 6 & 6 & 0 & 5 & 5 & 1 & 16 & -0.004 \\
\hline 5 & 3 & 3 & 4 & 2 & 3 & 55 & 2000 & 6 & 6 & 1 & 5 & 5 & 1 & 16 & -0.004 \\
\hline 5 & 4 & 2 & 4 & 3 & 1 & 5766 & -0.0 & 7 & 2 & 6 & 6 & 1 & 5 & 40 & 0.001 \\
\hline 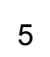 & 4 & 1 & 4 & 3 & 1 & 57 & -0.0 & 7 & 2 & 5 & 6 & 1 & 5 & & 0.005 \\
\hline 5 & 4 & 2 & 4 & 3 & 2 & 5767.9 & 0.0 & 7 & 3 & 5 & 6 & 2 & 4 & 07 & 0.004 \\
\hline 5 & 4 & 1 & 4 & 3 & 2 & 5768.0 & 000 & 7 & 3 & 4 & 6 & 2 & 4 & 37 & -0.003 \\
\hline 6 & 1 & 5 & 5 & 2 & 3 & 5873.956 & -0.007 & 7 & 3 & 5 & 6 & 2 & 5 & & -0.001 \\
\hline 5 & 5 & 1 & 4 & 4 & 0 & 5963.2 & 0.01 & 7 & 4 & 3 & 6 & 3 & 3 & 7788.325 & 0.000 \\
\hline 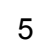 & 5 & 0 & 4 & 4 & 0 & 5963.219 & 0.011 & 7 & 4 & 4 & 6 & 3 & 4 & 7804.628 & -0.002 \\
\hline 5 & 5 & 1 & 4 & 4 & 1 & 5963.219 & -0.008 & 7 & 5 & 2 & 6 & 4 & 2 & 7995.019 & 0.008 \\
\hline 5 & 5 & 0 & 4 & 4 & 1 & 5963.219 & -0.008 & 7 & 5 & 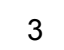 & 6 & 4 & 3 & 7995.765 & 0.014 \\
\hline
\end{tabular}

